\title{
An Ontology-Based Analysis and Semantics for Organizational Structure Modeling in the ARIS Method
}

\author{
Paulo Sérgio Santos Jr., João Paulo A. Almeida, Giancarlo Guizzardi \\ Ontology and Conceptual Modeling Research Group (NEMO) \\ Computer Science Department, Federal University of Espírito Santo (UFES) \\ Av. Fernando Ferrari, s/n, Vitória, ES, Brazil \\ paulossjunior@inf.ufes.br; jpalmeida@ieee.org; gguizzardi@acm.org
}

\begin{abstract}
This paper focuses on the issue of ontological analysis for organizational structure modeling in the ARIS method with the following contributions: (i) an interpretation of the language in terms of realworld entities in the UFO foundational ontology; (ii) the identification of inappropriate elements of the language, using a systematic ontology-based analysis approach; and (iii) recommendations for improvements of the language to resolve the issues identified.
\end{abstract}

Highlights: (i) We analyze organizational structure modeling in ARIS using a foundational ontology; (ii) We uncover ontological problems in the modeling of organizational structure in ARIS; (iii) We propose a semantics for organizational structure modeling as well as recommendations to address the issues identified.

Keywords: semantics for enterprise models; organizational structure; ontological analysis; ARIS; UFO (Unified Foundation Ontology)

\section{INTRODUCTION}

The need to understand and manage the evolution of complex organizations and its information systems has given rise to a number of Enterprise Architecture frameworks in the last decades, including Zachman's framework [62], TOGAF [66], DoDAF [15], MODAF [47], RM-ODP (with its Enterprise Viewpoint) [53], the ArchiMate framework [65] and the ARIS framework [56]. The majority of these frameworks considers an organization as a system whose elements include: (i) organizational activities structured in business processes and services; (ii) information systems supporting organizational activities; (iii) underlying information technology (IT) infrastructures, and, last but not least, (iv) organizational structures (revealing organizational actors, roles and organizational units).

The relevance of this last domain is clear from a management perspective in that it defines authority and responsibility relations between the various elements of an enterprise and enables one to consider the relations between multiple enterprises. Further, from an IT perspective, organizational actors can be considered system owners, system maintainers, system users or simply system stakeholders in general, affecting the usage and evolution of the enterprise's information systems. The importance of capturing organizational structures as part of enterprise architecture descriptions has long been recognized in enterprise architecture frameworks. For example, almost two decades ago, organizational structure elements have been included in the people (or "who") column of Zachman's framework [62], and in the organization view of the ARIS Method [12, 56].

Although present in most enterprise architecture frameworks, the semantics of organizational modeling elements is often ill-defined [1]. This is a significant challenge from the perspective of modelers who must select and manipulate modeling elements to describe an Enterprise Architecture and from the perspective of stakeholders who will be exposed to models for validation and decision making. In other words, a clear semantic account of the concepts underlying Enterprise Modeling languages is required for Enterprise Models to be used as a sound basis for the management, design and evolution of an Enterprise Architecture.

In this paper we are particularly interested in the modeling of this architectural domain in the widely employed ARIS Method (ARchitecture for integrated Information Systems). The ARIS framework is structured in terms of five different views (organization, data, control, function and output) and three abstraction layers (Requirements Definition, Design Specification and Implementation Description) [12, 56]. The organizational view in the requirements definition layer includes modeling concepts for the enterprise's 
structure (Organizational Unit, Position, Person, etc.) and its own diagrammatic language to produce Organization Charts (which we refer to here as the organizational language).

The ARIS organizational language is rich in terms of expressiveness, covering a wide range of concepts for organization modeling, including those for representing types of organizational units, organizational units, positions, position types, individuals, and the relations between those $[12,56]$. When contrasted with other enterprise modeling approaches, such as ArchiMate, DODAF, MODAF and BPMN, ARIS provides a richer set of constructs to relate organizational structure and business processes [3].

Although highly relevant in the industry and rich in terms of expressiveness, the ARIS organizational language is not without problems. For example, Fettke and Loos have discussed some issues arising from ambiguities in the organizational language in [18], concluding that certain intended meanings cannot be conveyed in the model, leading to potential confusion. Further, Davis observes in his ARIS book [13] when discussing the organizational elements that "it is best to severely restrict the objects available, otherwise people interpret them in different ways". Similar conclusions regarding problems in the ARIS languages have been observed by Green and Rosemann in [24], [25] and reported in [12].

In this paper, we address these problems systematically through ontological interpretation for the ARIS organization modeling elements with the following contributions: (i) providing real-world semantics to the modeling primitives of the organization language by using the well-founded UFO foundational ontology as a semantic domain; (ii) the identification of inappropriate elements of the organizational language, using ontology-based analysis $([26,27,33,58])$; and (iii) recommendations for improvements of the organizational language to resolve the issues identified (such as ontological mis-interpretations of the language elements and certain usage problems derived from semantic overload and construct redundancy [30]).

The interpretation discussed here is complementary to our previous work on a semantic foundation for process modeling in the ARIS method, in which we have addressed the process-related concepts of Event-driven Process Chains (EPCs) [54]. By providing a fuller analysis of the current ARIS metamodel, our work is complementary to the ontological analysis provided by Green, Rosemann and colleagues [24], [25]. (see section 6 for a detailed discussion on the relation between our approach and the one presented in [24], [25].).

To perform ontological interpretation and analysis, we use concepts of a philosophically and cognitively wellfounded reference ontology called Unified Foundational Ontology (UFO) discussed in depth in [30, 37] and a framework for language evaluation [69]. UFO unifies several foundational ontologies and has been employed to evaluate, re-design and integrate the models of conceptual modeling languages as well as to provide realworld semantics for their modeling constructs. For example, in [30] a complete evaluation and re-design of the UML 2.0 metamodel using UFO is presented, in [55] ARIS EPCs have been analyzed with UFO, in [4] the Motivation Extension proposed to ArchiMate was semantically analyzed, in [10] UFO was used to semantically integrate ARIS framework and TROPOS, and in [1] several enterprise modeling approaches are analyzed with UFO, with a focus on concepts to model role-related concepts. These ontological analyses have served to identify language issues and propose revisions and clarifications to address the issues identified.

This paper is organized as follows: section 2 provides some background on the ontological analysis approach we employ here; section 3 presents the metamodel for the ARIS organizational language, section 4 introduces the foundational ontology used in our analysis and section 5 provides an interpretation for each metamodel element in terms of this foundational ontology. Section 6 discusses related work and, finally, section 7 presents our conclusions and discusses future work.

\section{ONTOLOGical ANALYSIS}

Since the late 80 's there has been a growing interest in the use of foundational ontologies for evaluating and reengineering conceptual modeling languages and methodologies (see, e.g., the work of Wand and Weber in the construction and application of the BWW Ontology [67, 68]). The initial hypothesis, which has been later confirmed by a strong body of empirical evidence (see, e.g., [7, 23, 50, 59]) can be summarized as follows: (i) conceptual models, in general, and enterprise models, in particular, are artifacts produced with the goal of representing a part of a reality according to a certain conceptualization; (ii) a foundational ontology defines a system of domain-independent categories and their ties which can be used to articulate these conceptualizations of reality; Thus, a suitable conceptual modeling language should comprise modeling elements which reflect conceptual categories and relations defined in a foundational ontology. 
As discussed in [30,69], ontological analysis is performed by considering a mapping between modeling constructs and the concepts in an ontology (see Figure 1). On the one hand, each modeling element can be interpreted using the ontological theory as a semantic domain. On the other hand, concepts of the domain of discourse (captured in the ontological theory) should be represented by modeling elements of the language being considered. According to [69], there should be a one-to-one correspondence between the concepts in the ontology and modeling elements.

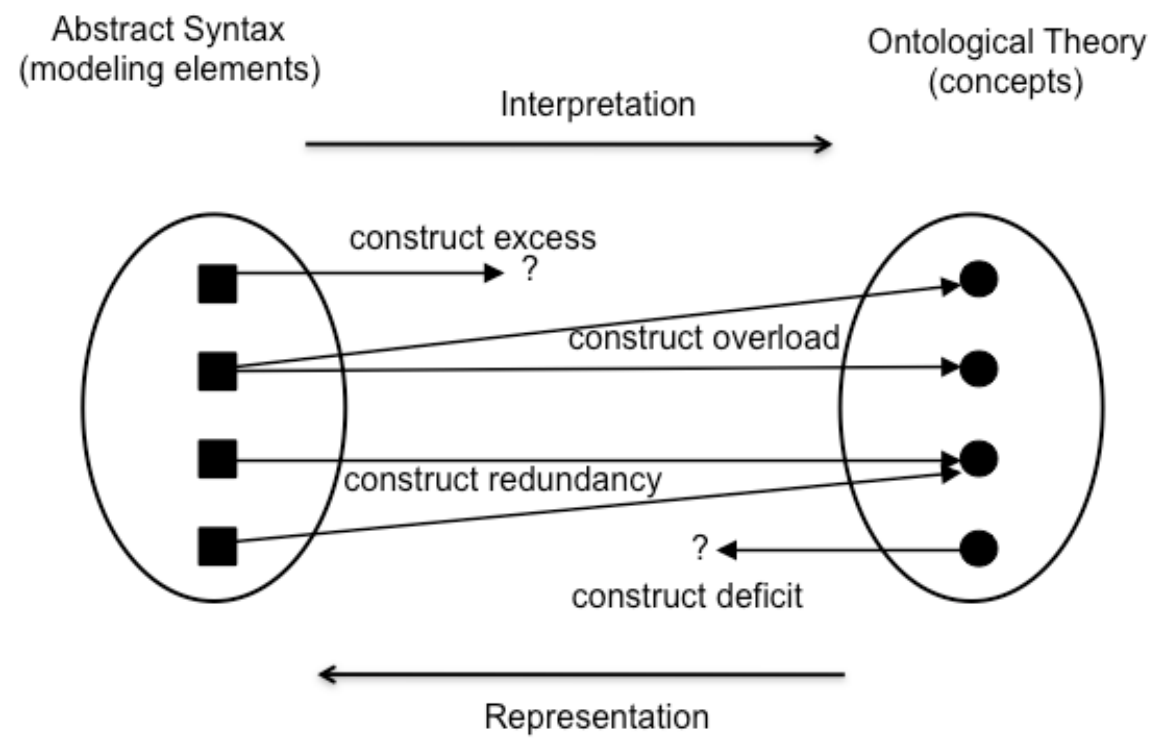

Figure 1 - Issues uncovered by ontological analysis (adapted from [48])

The following language problems can be identified when the correspondence cannot be obtained: construct excess, construct overload, construct redundancy and construct deficit:

Construct excess exists when a notation construct does not correspond to any ontological concept. Since no mapping is defined for the exceeding construct, its meaning becomes uncertain, hence, undermining the clarity of the specification. According to [69], users of a modeling language must be able to make a clear link between a modeling construct and its interpretation in terms of domain concepts. Otherwise, they will be unable to articulate precisely the meaning of the specifications they generate using the language. Therefore, a modeling language should not contain construct excess and every instance of its modeling constructs must represent an individual in the domain.

Construct overload exists when a single notation construct can represent multiple ontological concepts. Construct overload impacts language clarity negatively. Construct overload is considered an undesirable property of a modeling language since it causes ambiguity and, hence, undermines clarity. When a construct overload exists, users have to bring additional knowledge not contained in the specification to understand the phenomena which are being represented.

Construct redundancy exists when multiple modeling elements can be used to represent a single ontological concept. Construct redundancy is a violation of parsimony. In [69], Weber claims that construct redundancy "adds unnecessarily to the complexity of the modeling language" and that "unless users have in-depth knowledge of the grammar, they may be confused by the redundant construct. They might assume for example that the construct somehow stands for some other type of phenomenon." Therefore, construct redundancy can also be considered to undermine representation clarity.

Construct deficit exists when there is no construct in the modeling language that corresponds to a particular ontological concept. Construct deficit entails lack of expressivity, i.e., that there are phenomena in the considered domain (according to a domain conceptualization) that cannot be represented by the language. Alternatively, users of the language can choose to overload an existing construct, thus, undermining clarity.

A number of enterprise modeling approaches have been subject to ontology-based analysis in recent years (e.g., [12, 21, 27, 26, 36, 40, 42, 43, 51]). Recently, Recker et al. [50] have reported results from a study with 528 modelers that show that "users of conceptual modeling grammars perceive ontological deficiencies to 
exist, and that these deficiency perceptions are negatively associated with usefulness and ease of use of these grammars." Given the importance of perceived usefulness and ease of use for language acceptance, these results emphasize the practical impact of ontological analysis.

\section{THE ARIS ORganizational MetaMOdEL}

We adopt here the organizational metamodel which has been excavated in our earlier work [55], in which we focused solely on the abstract syntax (and not on the semantics) of the organizational language. The metamodel captures the elements currently supported by the ARIS Toolset. We have maintained the terminology employed in the ARIS Toolset and aimed at representing the abstract syntax that is available for users of the ARIS Method. The metamodel we employ here is more up-to-date when compared to the organizational metamodel defined originally by Scheer [56]. The latter includes some elements that are not implemented in the tools (e.g., Object Organization and Profile Organization) and leaves out some of the elements currently supported by the tools (e.g., various meta-associations).

The main metaclasses for the organization modeling language are: Organizational Unit, Organizational Unit Type, Position, Person, Person Type, Group and Location. We present the organizational metamodel by describing these main metaclasses using as sources of documentation the main literature on ARIS ([13, 56]) and the ARIS Toolset online documentation, which is the source of our quotes in the remainder of this section. We focus here on the metaclasses and defer the discussion of the meta-associations to section 4 , as there are no explicit definitions for the meta-associations in the available documentation, with no further description provided in addition to their labels.

Figure 2 presents an overview of the organizational language's abstract syntax represented in an ECORE metamodel and depicted using a UML class diagram. Navigability is used solely to assist the reading of association labels. All omitted cardinalities (on non-navigable association ends) should be interpreted as zeroto-many.

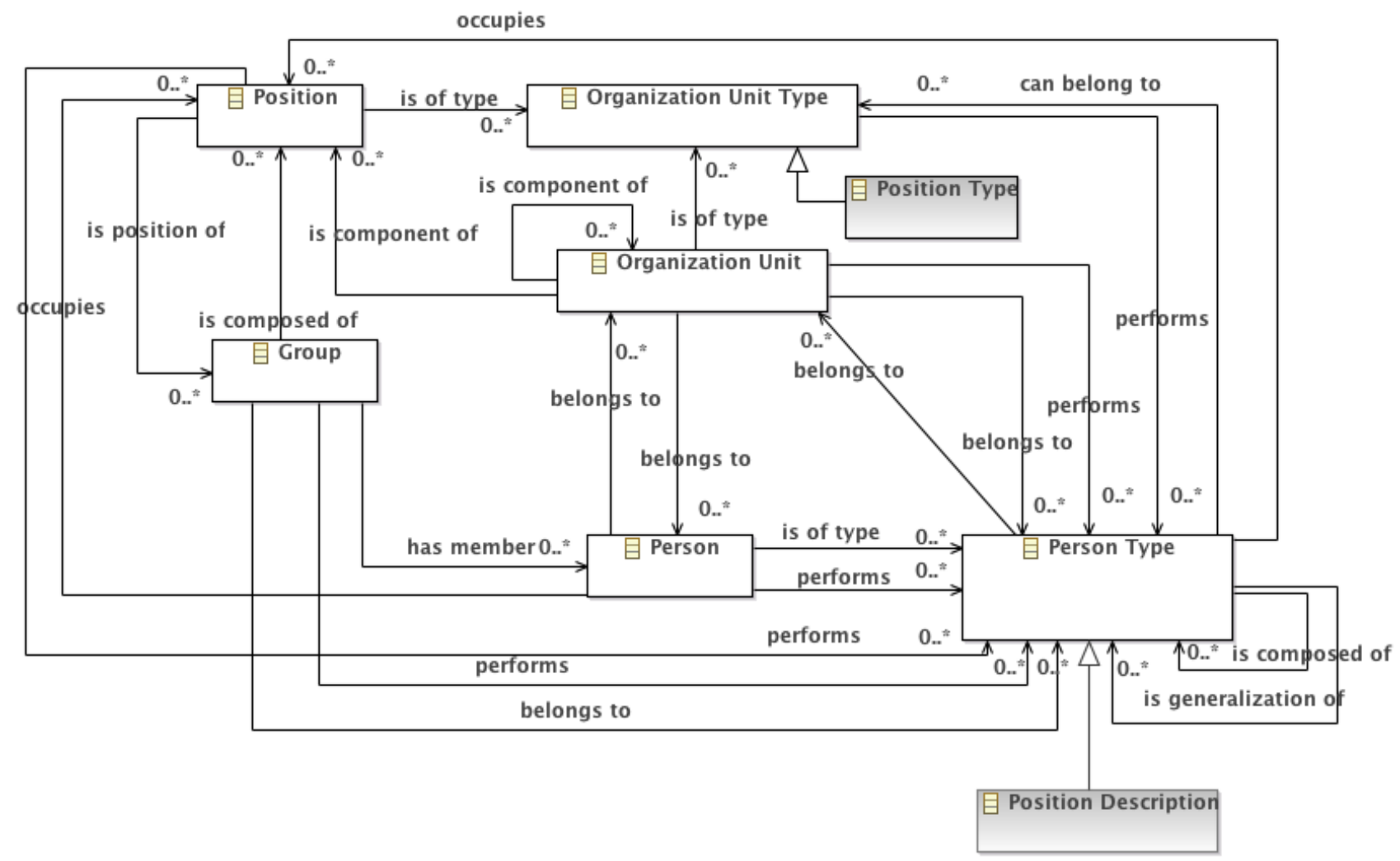

Figure 2. Fragment of Organizational metamodel of ARIS Method

The Organizational Unit metaclass represents "an entity that is responsible for achieving organizational goals (organization unit)." Examples of organizational units are the "Federal University of Espírito Santo", the "Accounting Department of the Federal University of Espírito Santo", the "Brazilian Federal Senate" and the "Brazilian Chamber of Deputies" (which together make up the "Brazilian National Congress"). 
An example of Organizational Chart (from [56]) is depicted in Figure 3, revealing the following organizational units: "Sample Co. Inc", its "Sales" Department, its "Billing" and its "Shipping" Department.

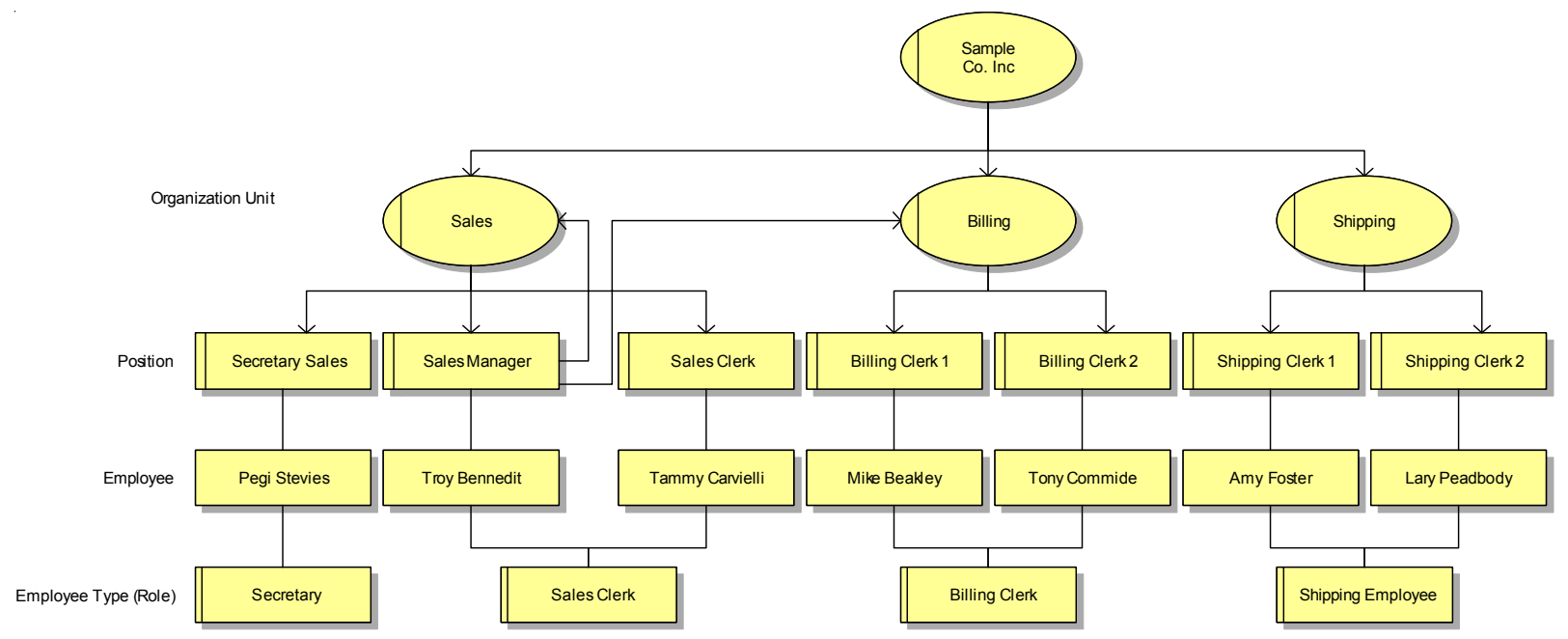

Figure 3. Example of Organizational modeling in Organizational Chart ([56],p.187)

The Organizational Unit Type metaclass represents "a type of organization unit, i.e., an element that represents the common features (duties, responsibilities, etc.) of a set of organization units". Examples of Organizational Unit Types are "University", "Federal University", "Federal Senate", "Chamber of Deputies" and "Accounting Department".

The Position metaclass represents "the smallest organizational unit possible. The responsibilities and duties of a position (Position) are defined in the Position Description". (This is represented here in gray to denote that it is a specialization of Person Type that is applied through the default filter in the toolset.) Examples of Positions include "Assistant Professor", "Associate Professor", "Full Professor", "Senator" and "Accountant". Examples of Positions in an Organizational Chart are shown in Figure 3: "Secretary Sales", "Sales Manager", "Sales Clerk", "Billing Clerk1", "Billing Clerk2", "Shipping Clerk1" and "Shipping Clerk2".

The Position Type metaclass represents a "type of position, i.e. an element that represents the common features (duties, responsibilities, etc.) of a set of positions". Examples include "Professor" and "Member of Congress".

The Person metaclass "is used to represent a person who is assigned to an organization". Examples of Person are "Pegi Stevies", "Troy Bennedit", "Tammy Cavielli", etc. in Figure 3. (Please note that Figure 3 uses outdated terminology for Person and Person Type, calling these elements Employee and Employee Type instead.)

According to the on-line documentation of ARIS Toolset the Person Type metaclass represents "a generalization of person, i.e., an element that represents the common features (duties, responsibilities, feature, etc.) of a set of people”.

The Group metaclass represents "a group of employees (Person) or a group of organizational units (Organizational Unit) that work together to achieve a goal, e.g., a group of senators and deputies in a parliamentary inquiry committee.

The Location metaclass (shown in Figure 4, using the same conventions of Figure 2) represents " $a$ geographical location of an organization unit, person, position, group, person type". A Location element can represent a region, a city or a building, e.g., "Vitória", "Brazil", "Brasília" and the "Building of the Brazilian National Congress." 


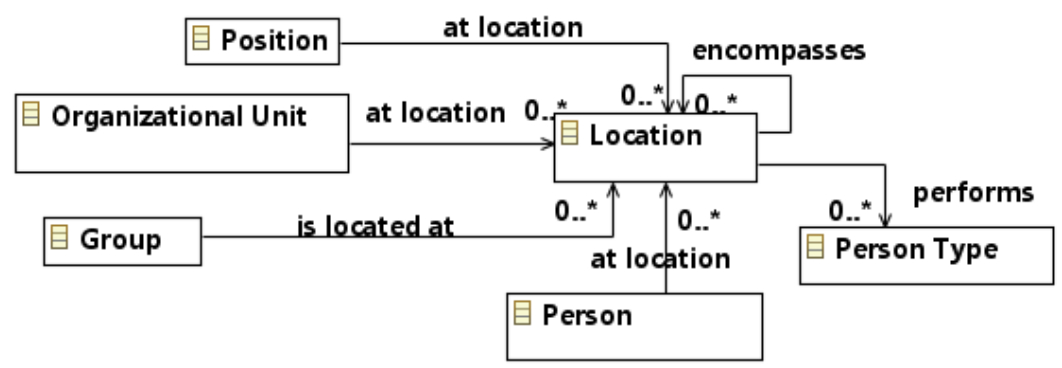

Figure 4. Fragment of the organizational metamodel concerning Location

Unfortunately, the on-line documentation of ARIS Toolset and the main literature on ARIS is not explicit about the semantics of the meta-associations present in the metamodel. Thus, we discuss possible interpretations for of each meta-association later in light of the ontological foundations presented in the sequel.

\section{ONTOLOGiCAL FOUNDATIONS}

Before we perform an analysis of the enterprise language concepts, we present here an ontological foundation on which we base our analysis. We will use concepts of a reference ontology called Unified Foundational Ontology (UFO) discussed in depth in [30, 35, 37]. UFO started as a unification of the GFO (Generalized Formalized Ontology) and the Top-Level ontology of universals underlying OntoClean [29]. However, as shown in [30], there are a number of problematic issues related the specific objective of developing ontological foundations for general conceptual modeling languages which were not covered in a satisfactory manner by existing foundational ontologies such as GFO, DOLCE [16] or OntoClean. For this reason, UFO has been developed into a full-blown reference ontology based on a number of theories from Formal Ontology, Philosophical Logics, Philosophy of Language, Linguistics and Cognitive Psychology. Thus, the goal behind the engineering of UFO has been to formally organize a reference ontology with the specific purpose of providing foundations for the distinctions underlying conceptual modeling languages and methodologies. Accordingly, UFO has been based on philosophically well-founded principles, but ones that capture the ontological distinctions underlying human cognition and common sense. Extensive discussion on the philosophical work that has influenced the reference ontology can be found in [30], as well as the position of UFO with respect to several alternative foundational ontologies. This includes the aforementioned foundational ontologies, but also (systematically) the BWW ontology [67, 68]. A discussion on the basic criteria to justify the usage of theories and empirical evidence from cognitive sciences in the design of the reference ontology can be found in [28].

We focus here on the UFO fragment concerned with aspects of social reality and intentionality, as these aspects are pervasive in the organizational environments that form the universe of discourse of the organizational structure. We present only those elements needed for our ontological analysis, starting from the basic ontological distinctions in UFO's core and then proceeding to the layer of intentional concepts and the layer of social concepts. We also discuss whole-part relations as these are important in an account of hierarchical organizational structure.

\subsection{Basic Elements}

We start with the fundamental distinction between universals and individuals. The notion of universal underlies the most basic and widespread constructs in conceptual modeling. Universals are predicative terms that can possibly be applied to a multitude of individuals, capturing the general aspects of such individuals. Individuals are entities that exist instantiating a number of universals and possessing a unique identity. Individuals can be further classified into Endurants and Events (also known as Perdurants).

Endurants are individuals said to be wholly present whenever they are present. Endurants are in time in the sense that if we say that in circumstance $\mathrm{c} 1$ an endurant e has a property $\mathrm{P} 1$ and in circumstance $\mathrm{c} 2$ the property P2 (possibly incompatible with $\mathrm{P} 1$ ), it is the very same endurant e that we refer to in each of these situations. Examples of endurants include a house, a person, the moon, and an enterprise. 
A fundamental distinction in UFO is between the categories of Substantials and Moments. A Substantial is an Endurant that does not depend existentially on other Substantials ${ }^{1}$, roughly corresponding to what is referred by the common sense term "object". In contrast with Substantials, we have Moments which are existentially dependent entities. For a Moment $\mathrm{x}$ to exist, another individual must exist, named its bearer. Examples of Substantials include a person, a house, a planet, and the Rolling Stones; examples of Moments include John's weight and John and Mary's marriage. Existential dependence can also be used to differentiate Intrinsic Moments Relational Moments (or Relators). Moments are classified into Intrinsic Moments when existentially dependent on a single entity and Relators otherwise. Examples of the intrinsic moments include a (objectified) color, a headache, a temperature; examples of the relators include an employment, a covalent bond, and a marriage. For instance, John and Mary's marriage is an example of a Relator that is dependent on both John and Mary.

An attempt to model the relation between intrinsic moments and their representation in human cognitive structures is presented in the theory of conceptual spaces introduced in [22]. The theory is based on the notion of quality dimension. The idea is that for several perceivable or conceivable quality universals there are associated quality dimensions in human cognition. For example, height and mass are associated with onedimensional structures with a zero point isomorphic to the half-line of nonnegative numbers. Other properties such as color and taste are represented by multi-dimensional structures. Moreover, the author distinguishes between integral and separable quality dimensions: "certain quality dimensions are integral in the sense that one cannot assign an object a value on one dimension without giving it a value on the other. For example, an object cannot be given a hue without giving it a brightness value (...) Dimensions that are not integral are said to be separable, as for example the size and hue dimensions." He then defines a quality domain as "a set of integral dimensions that are separable from all other dimensions" [22]. Furthermore, he defends that the notion of conceptual space should be understood literally, i.e., quality domains are endowed with certain geometrical structures (topological or ordering structures) that constrain the relations between its constituting dimensions. Finally, the perception or conception of an intrinsic moment can be represented as a point in a quality domain. In line with [44], this point is named here a quale.

We adopt in this work the term quality structures to refer to quality dimensions and quality domains, and we define the formal relation of association between a quality structure and an intrinsic moment universal. Additionally, we use the terms quality universals for those intrinsic moment universals that are directly associated with a quality structure, and the term quality for an intrinsic moment classified under a quality universal. Furthermore, we define the relation of valueOf connecting a quality to its quale in a given quality structure.

Another important distinction in the UFO ontology is within the categories of relations. Following the philosophical literature (e.g., [38], [49]), it recognizes two broad categories of relations, namely, material relations and formal relations. Formal relations hold between two or more entities directly, without any further intervening individual. Examples include the relations of existential dependence (ed), Subtype, instantiation $(::)$, formal parthood $(<)$, inherence (i), among many others not discussed here [30]. Domain relations such as working at, being enrolled at, and being the husband of are of a completely different nature. These relations, exemplifying the category of Material relations, have material structure of their own ${ }^{2}$. Whilst a formal relation such as the one between Paul and his headache $\mathrm{x}$ holds directly and as soon as Paul and x exist, for a material relation of being treated in between Paul and the medical unit MU1 to exist, another entity must exist which mediates Paul and MU1. These entities are termed relators.

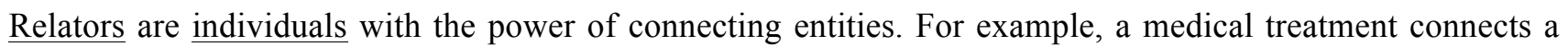
patient with a medical unit; an enrolment connects a student with an educational institution; a covalent bond connects two atoms. Again, relators are special types of moments which, therefore, are existential dependent entities. The relation of mediation (symbolized $\mathrm{m}$ ) between a relator $\mathrm{r}$ and the entities $\mathrm{r}$ connects is a sort of

\footnotetext{
${ }^{1}$ Technically, a substantial does not existentially depend on other substantials, which are disjoint from it [30].

${ }^{2}$ As discussed in [30], the distinction between formal and material relations is analogous to another distinction among relations, namely the one between bonding and non-bonding relations as proposed by Bunge. For Bunge, bonding relations are the ones that alter the history of the involved relata.
} 
(non-exclusive) inherence and, hence, a special type of existential dependence relation. It is formally required that a relator mediates at least two distinct individuals [30].

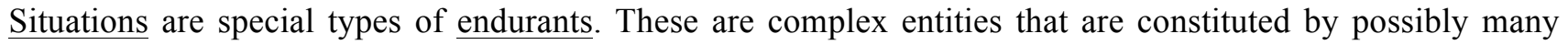
endurants (including other situations). Situations are taken here to be synonymous to what is named state of affairs in the literature [64], i.e., a portion of reality that can be comprehended as a whole. Examples of situations include "John being with fever and influenza", "John being in the same location as Paul while Mary is in the same location as David", "Mary being married to Paul who works for the University of Twente".

Events (Perdurants), in contrast with Endurants, are individuals composed by temporal parts, they happen in time in the sense that they extend in time accumulating temporal parts. An example of an Event is a business process. Whenever an Event occurs, it is not the case that all of its temporal parts also occur. For instance, if we consider a business process "Buy a product" at different time instants when it occurs, at each of these time instants only some of its temporal parts are occurring. Finally, we can consider Events as possible transformations from a portion of reality to another, i.e., they may change reality by changing the state of affairs from one (pre-state) situation to a (post-state) situation.

\subsection{Universals}

Among the category of substantial universals, UFO distinguishes between sortals and non-sortal universals. Whilst all universals carry a principle of application, only sortals carry a principle of identity for their instances. A principle of application is a principle for which we can judge whether an individual is an instance of that universal. In contrast, a principle of identity is a principle for which we can judge whether two individuals are the same. As an illustration of this point, contrast the two universals Person and Physical Object instantiated by two individuals $\mathrm{x}$ and $\mathrm{y}$ : both universals supply a principle for which we can judge whether $\mathrm{x}$ and $\mathrm{y}$ are classified under those types (i.e., whether they are Persons, or Physical Objects). However, only Person supplies a principle for which we decide whether $\mathrm{x}$ and $\mathrm{y}$ are the same (i.e., merely knowing that $\mathrm{x}$ and $\mathrm{y}$ are both Physical Objects gives no clue to decide whether or not $\mathrm{x}=\mathrm{y}$ ).

In a distinction orthogonal to the one between sortals and non-sortals, we differentiate between rigid and antirigid universals: A universal $U$ is rigid if for every instance $x$ of $U, x$ is necessarily (in the modal sense) an instance of $U$. In other words, if $x$ instantiates $U$ in a given world $w$, then $x$ must instantiate $U$ in every possible world w'. In contrast, a universal $\mathrm{U}$ is anti-rigid if for every instance $\mathrm{x}$ of $\mathrm{U}, \mathrm{x}$ is possibly (in the modal sense) not an instance of $U$. In other words, if $x$ instantiates $U$ in a given world $w$, then there must be a possible world w" in which $\mathrm{x}$ does not instantiate $\mathrm{U}$.

A sortal universal which is rigid is named here a kind. In contrast, an anti-rigid substantial universal is termed here a phased-sortal [30]. The prototypical example highlighting the modal distinction between these two categories is the difference between the kind Person and the phase-sortals Student and Adolescent instantiated by the individual John in a given circumstance. Whilst John can cease to be a Student and Adolescent (and there were circumstances in which John was not one), he cannot cease to be a Person. In other words, while the instantiation of the phase-sortals Student and Adolescent has no impact on the identity of a particular, if an individual ceases to instantiate the universal Person, then he ceases to exist as the same individual.

In the example above, John can move in and out of the Student universal, while being the same individual, i.e. without losing his identity. This is because the principle of identity that applies to instances of Student and, in particular, that can be applied to John, is the one which is supplied by the kind Person of which the phase-sortal Student is a subtype. This is always the case with phased-sortals, i.e., for every phased-sortal PS, there is a unique ultimate kind $\mathrm{K}$, such that: (i) PS is a specialization of K; (ii) $\mathrm{K}$ supplies the unique principle of identity obeyed by the instances of PS. If PS is a phased-sortal and K is the kind specialized by PS, there is a specialization condition $\varphi$ such that $\mathrm{x}$ is an instance of PS iff $\mathrm{x}$ is an instance of $\mathrm{K}$ that satisfies $\varphi$.

A particular type of phased-sortal emphasized in this article is what is named in the literature a role. A role Rl is anti-rigid object type which specialization condition $\varphi$ is an extrinsic (relational) one. For example, one might say that if John is a Student then John is a Person who is enrolled in some educational institution, if Peter is a Customer then Peter is a Person who buys a Product $\mathrm{x}$ from a Supplier $\mathrm{y}$, or if Mary is a Patient than she is a Person who is treated in a certain medical unit. In other words, an entity plays a role in a certain context, demarcated by its relation with other entities. This meta-property of roles is named relational dependence and can be formally characterized as follows: A universal $\mathrm{T}$ is relationally dependent on another 
universal $\mathrm{P}$ via relation $\mathrm{R}$ iff for every instance $\mathrm{x}$ of $\mathrm{T}$ there is an instance $\mathrm{y}$ of $\mathrm{P}$ such that $\mathrm{x}$ and $\mathrm{y}$ are related via $\mathrm{R}[30]$.

In summary, sortals carry a uniform principle of identity obeyed by all their instances. Thus, either a sortal is a Kind or it specializes a unique kind, thus, inheriting the principle of identity supplied by that Kind. In other words, for every sortal S, all instances of S are instance of the very same kind $\mathrm{K}$ and, hence, obey the principle of identity supplied by K. A non-sortal, in contrast, is a type which classifies instances of different kinds obeying different principles of identity. For this reason, a non-sortal is also termed a dispersive universal [30].

A non-sortal $\mathrm{T}$ always describes common properties of instances of multiple kinds. These properties can be necessary (in the modal sense) to all instances of $\mathrm{T}$, thus, making of $\mathrm{T}$ a rigid non-sortal. In contrast, $\mathrm{T}$ can aggregate properties which are contingent to all instances, thus, making of $\mathrm{T}$ an example of anti-rigid nonsortal. A specific sort of anti-rigid non-sortal of relevance to this article is what is termed a role mixin. A role mixin represents an anti-rigid and externally dependent non-sortal, i.e., a dispersive universal that aggregates properties which are common to different roles. An example of role mixin is Customer since: (i) it is contingent to all its instances - no Customer is necessarily a Customer; (ii) it is relationally dependent - one is Customer in the context of a relation to a Supplier; (iii) it is dispersive, i.e., it has instances that belong to different kinds, namely, Persons and Organizations. Finally, the non-sortal $\mathrm{T}$ can aggregate properties which are necessary to some of its instances and contingent to others. This meta-property is termed Semi-Rigidity in [30]. In UFO, a semi-rigid non-sortal is termed a mixin. An example of a mixin can be offered as follows: suppose that in a given conceptualization all Cars must be insured. Moreover, suppose that only expensive houses (houses which cost more than 2 Million Euros) must be insured. Furthermore, suppose that being expensive (in the aforementioned sense) is a contingent property of houses, i.e., the type ExpensiveHouse is a phased-sortal. Now, we have that: (i) both instances of Car and ExpensiveHouse are instances of InsuredItem, i.e., InsuredItem is a non-sortal; (ii) however, being an insured item is a necessary property of Cars but merely a contingent property of Houses. In summary, a mixin is a non-sortal that aggregates properties which are common to a mixture of rigid and anti-rigid types. The type InsuredItem above being an example.

Finally, the discussion above is restricted to the so-called First-Order Universals, i.e., universals whose instances are concrete individuals. In contrast, a High Order Universal is a universal whose instances are universals. Examples of higher-order universals are "Bird Species" (whose instances could be "Parrot" and "Penguin", both Universals), and "Type of Organization" (whose instances could be "For-Profit Organization" and "Not-For-Profit Organization", also both universals).

\subsection{Intentional Elements}

UFO has been extended to incorporate intentionality to this basic core $[35,37]$. In this context, UFO distinguishes between Agentive and Non-agentive substantial individuals, termed here Agents and Objects, respectively.

Agents are substantials capable of bearing special kinds of moments named Intentional Moments. As argued in [57], intentionality should be understood in a much broader context than the notion of "intending something", but as the capacity of some properties of certain individuals to refer to possible situations of reality.

Every intentional moment has a type (e.g., Belief, Desire, Intention) and a propositional content. The latter being an abstract representation of a class of situations referred by that intentional moment. The precise relation between an intentional moment and a situation is the following: a situation in reality can satisfy the propositional content of an intentional moment (i.e., satisfy - in the logical sense - the proposition representing that propositional content).

Whilst a desire expresses a will of an agent towards a state of affairs in reality (e.g., a Desire that Brazil wins the Next World Cup), intentions are desired state of affairs for which the agent commits at pursuing (an intention is an internal commitment) (e.g., the Intention of going to a beach resort for the next summer break) $[11,57]$.

Actions are intentional events, i.e., events with the specific purpose of satisfying (the propositional content of) some Intention of an Agent. (In this sense, an Action can be said to be caused by the Intention.) The propositional content of an intention is termed a Goal. UFO contemplates a relation between Situations and 
Goals such that a Situation (or possibly a number of Situations) may satisfy a Goal. In other words, since a Goal is a proposition (the propositional content of an Intention), we have that a particular state of affairs can be the truthmaker of that proposition.

Figure 5 shows a fragment of UFO (adapted from [30] and [37]), with an emphasis on the distinctions discussed so far (categories of universals are depicted in Figure 6).

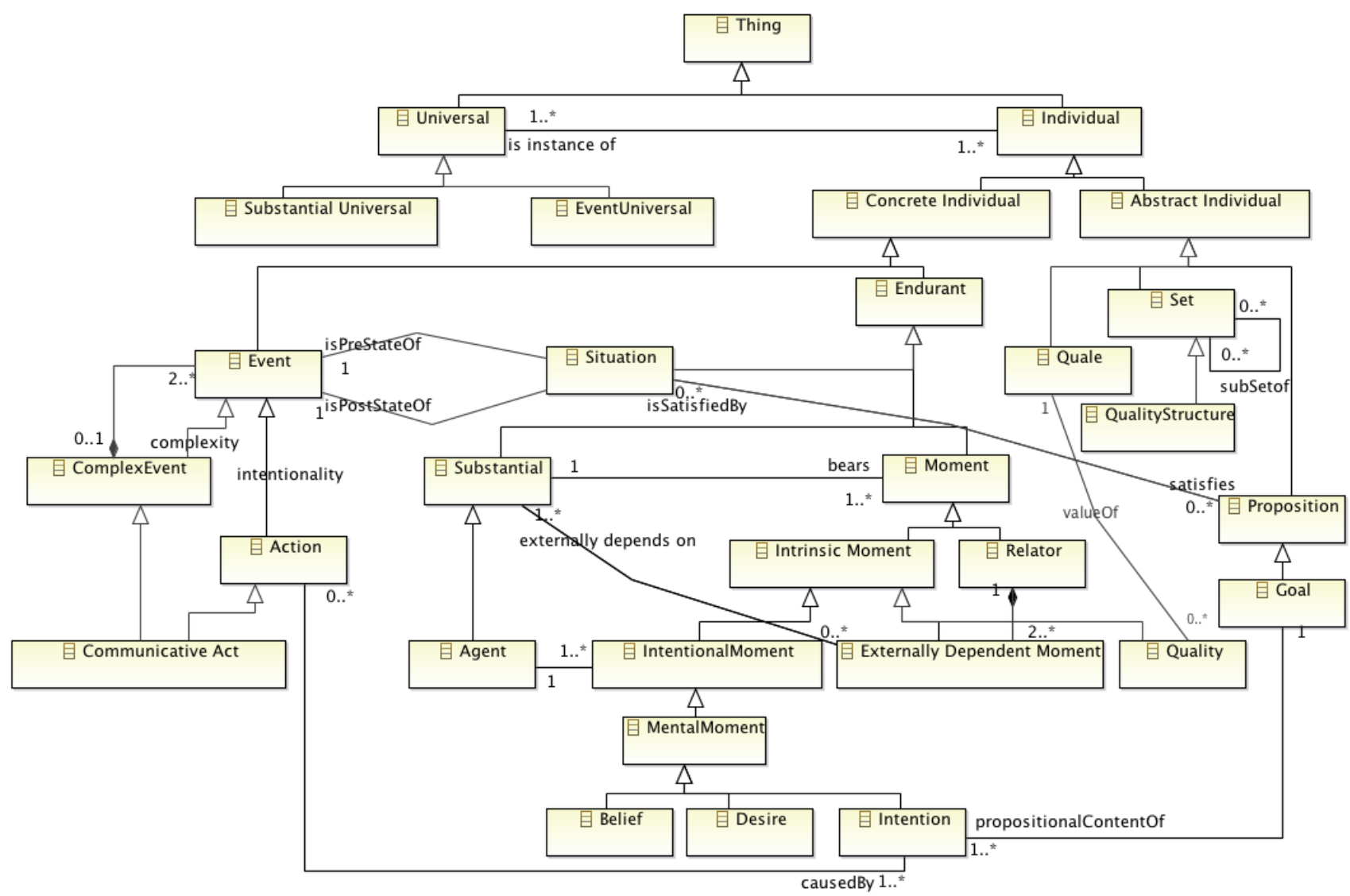

Figure 5 - UFO Fragment (adapted from [30] and [37])

\subsection{Social Elements}

Communicative Acts (special kinds of Actions) can be used to create Social Moments. In this view, language not only represents reality but also creates a part of reality [57]. Thus, social moments are types of intentional moments that are created by the exchange of communicative acts and the consequences of these exchanges (e.g., goal adoption, delegation [36]). For instance, suppose that John rents a car at a car rental service. When signing a business agreement, John performs a communicative act (a promise). This act creates a Social Commitment towards that organization: a commitment to return the car in a certain state, etc. (the propositional content). Moreover, it also creates a Social Claim of that organization towards John with respect to that particular propositional content. Commitments/Claims always form a pair that refers to a unique propositional content.

A Social Relator is an example of a relator composed of two or more pairs of associated commitments/claims (social moments). Finally, a commitment (internal or social) is fulfilled by an agent A if this agent performs an action $\mathrm{x}$ such that the post-state of that action is a situation that satisfies that commitment.

Communicative Acts can also be used to distinguish between Physical Agents (e.g., a person, a dog) and Social Agents (e.g., an organization, a society). Social Agents are created by communicative acts. In an analogous manner, objects can also be categorized as Physical Objects (e.g., cars, rocks and threes) or Social Objects (e.g., a currency, a language, the Brazilian constitution). Social Agents are composed by a number of other agents, which can themselves be Physical Agents, or other Social Agents. When Social Agents are integral wholes formed by multiple agents playing different roles they are further classified as Institutional Agents. An Institutional Agent exemplifies what is named a Functional Complex, i.e., a mereologically 
complex entity whose parts play different roles with respect to the whole. By instantiating each of these roles defined in the characterization of that Functional Complex Universal, each part contributes in a different way to the integral behaviour of the whole.

Communicative Acts can result in social objects called Normative Descriptions. The characteristics of descriptions have been discussed in [46], including (among others) that: "descriptions are created by (communities of) intentional agents at the time of their first encoding in an expression of a 'public' (formal or informal) language"; "descriptions are usually accepted (adopted) by (communities of) intentional agents" and "acceptation can change in time." In the case of a social functional complex such as an Institutional Agent, the characterization of the universal instantiated by that agent is made via a Normative Description [8], which is said to define the institutional agent (including its Social Roles (e.g., president, manager, sales representative), Social Agent Universals (e.g., a political party, an education institution), Social Agents (e.g., the Brazilian Labour Party), Social Object Universals and other Social Objects (e.g., a piece of legislation, a currency) or other Normative Descriptions. Figure 6 shows a fragment of UFO (adapted from [30] and [37]) focusing on the social elements of the ontology.

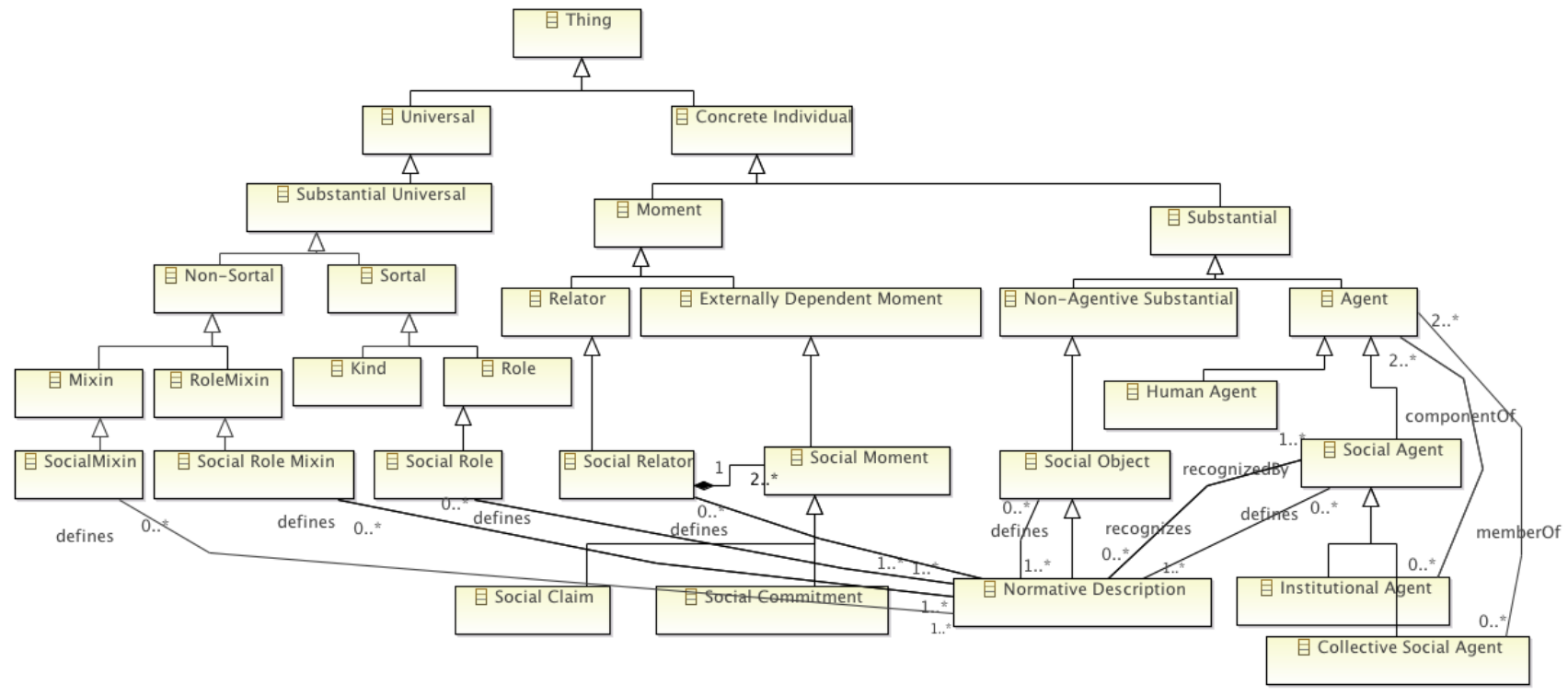

Figure 6 - UFO Fragment (adapted from [30] and [37])

\subsection{Whole-Part Relations}

In practically all formal theories of parts (mereologies), the relation of (proper) parthood stands for a strict partial ordering, i.e., irreflexive, asymmetric and transitive relation [61]. Although necessary, these constraints are not sufficient, i.e., it is not the case that any partial ordering relation qualifies as a parthood relation. Most authors require at least an extra axiom termed the weak supplementation principle, which basically requires that if an entity is not atomic then it must be composed of at least two disjoint parts [61]. The theory which incorporates the strict partial-order axioms plus weak supplementation principle is termed minimum mereology. However, for certain kinds of entities (e.g., quantities, events), a theory even stronger than minimum mereology is required, named extensional mereology. Extensional mereology strengths minimum mereology by including the so-called strong supplementation principle which implies an extensional principle of identity for entities that have a mereological structure governed by this theory. So, according to extensional mereology, two entities are the same if, and only if, they are composed by exactly the same parts.

As discussed in depth in [30], although mereological theories can provide sound and characterized formal semantics for whole-part relations, they are not sufficient to fully characterize the many different aspects of conceptual whole-part relations. These aspects include different modal properties of whole-part relations: for instance, while some whole-part relations characterize a relation of generic dependence, termed mandatory parthood (e.g., a car must have a carburetor), other whole-part relations characterize a relation of specific (or existential) dependence, termed essential parthood (e.g., a car must have that very specific chassis). 
Another important aspect fundamental for a conceptual theory of whole-part relation is the characterization of complex entities as integral wholes. According to Simons [61], the difference between purely formal mereological sums and, what he terms, integral wholes is an ontological one, which can be understood by comparing their existence conditions. For sums, these conditions are minimal: the sum exists just when the constituent parts exist. By contrast, for an integral whole (composed of the same parts of the corresponding sum) to exist, a further unifying condition among the constituent parts must be fulfilled. A unifying condition or relation can be used to define a closure system, i.e., a (perhaps complex) relation holding between the components of that whole and only between them. In other others, classical mereological theories focus solely on the relation from the parts to the wholes. As discussed in [30], in conceptual theory of parthood we must also account for the relations holding between the parts that compose a whole.

Another aspect that should be accounted for is the fact that cognitively speaking, parthood is not a single relation but four distinct relation types, namely: (a) subquantity-quantify (e.g., alcohol-wine) - modeling parts of an amount of matter which are unified in a whole due to a topological connection relation; (b) membercollective (e.g., a specific tree - the black forest) - modeling a collective entity in which all parts play an equal role with respect to the whole; (c) subcollective-collective (e.g., the north part of the black forest- the black forest); (d) component - functional complex (e.g., heart-circulatory system, engine - car) - modeling an entity in which all parts play a different role with respect to the whole, thus, contributing to the functionality of the latter.

As discussed in depth in [31], the componentOf relation connecting functional complexes to their parts is a complex relation implying both a formal mereological relation and a relation of Functional Dependence. So, for instance, the relation between a particular Body (a functional complex) and a particular Heart denotes a relation of parthood but also represents the fact that for the body to work as functioning body, there must be a Heart playing the role of a Blood Pump (i.e., a Heart exhibiting the behaviour of a Heart-qua-blood-pump) [31]. Moreover, componentOf is not itself a formal relation but a material one: the fact that Brazil is part of the United Nations or the fact that Paul's transplanted heart is part of his body demand for the existence of founding events and consequent relators. So, a Functional Complex Universal is characterized by a complex of Functional Roles (and implicit Relator and Qua Individual Universals) such that a Functional Complex Individual is an Integral Whole unifying all those entities that in a given circumstance play (instantiate) those Functional Roles. Finally, as formally demonstrated in [31], componentOf cannot be considered a classical mereological relation, since unlike all classical mereological relations, unrestrictive transitivity does not hold for componentOf. For instance, while Paul's heart is part of Paul and Paul is part of the Liverpool FC, Paul's heart is not part of the Liverpool FC. The chain of transitivity of the componentOf relation is restricted to certain scopes. Patterns to isolate these scopes of restrictive transitivity for a given situation are formally proved in [31].

\section{Ontological ANalysis of the ARis Organizational StruCture Elements}

We proceed to analyze the organizational structure elements of ARIS. We address each of the main metaclasses and focus on the meta-associations representing instantiation, specialization and whole-part relations.

\subsection{Organization Unit, Organizational Unit Type and Position}

The Organizational Unit metaclass in ARIS represents a UFO Institutional Agent. This is because Organizational Units are agentive entities that may be composed of other agentive entities (such as other Organizational Units through the is component of meta-association, and, in the end of the decomposition hierarchy Positions as revealed through the is composed of meta-association). These parts (Organizational Units and Positions) play specific roles in this institutional agent, which supports our interpretation.

Organizational Units are "social" agents since they are defined by Normative Descriptions. In the case of an entire organization (an "enterprise") represented as an Organizational Unit in ARIS this Normative Descriptions is recognized by the organized society (a Collective Social Agent), which defines what counts as that organization. In the case of a particular sub-division of an organization, this Normative Description is recognized by the organization and its members.

The Organizational Unit Type element is interpreted as an Institutional Agent Universal, capturing general characteristics of Organizational Units. The is of type meta-association between Organizational Unit and 
Organizational Unit Type is interpreted as instantiation. Instantiation is a Formal Relation which occurs between a Universal and a Particular and has the following semantics: "When we say that $p$ is an instance of $U$, we are willing to represent that $p$ has the property of being a $U$ " [30].

Again, Organizational Units Types are "social" Universals since they are defined by Normative Descriptions and are considered to exist for the Agents that recognize these Normative Descriptions.

According to the ARIS literature ([13] and [56]), "a position is the smallest organizational unit". If we follow this definition literally, we may be tempted to suggest that a Position should be interpreted as an Institutional Agent (our interpretation for Organizational Unit.) However, this interpretation is problematic because a Position would be an Institutional Agent that cannot be further decomposed into smaller parts: a Position can only be occupied by a Person. (This can be observed in the metamodel, through the occupies metaassociation between Person and Position.) In other words, a Position would be a whole (a Functional Complex) that is composed of only one part (a single Agent), breaking the weak supplementation principle [30]. In other words, why should one distinguish the institutional agent that corresponds to the Position from the actual agent in that Position? [1] Further, it seems that the intention of the language designers was to capture in a Position some general characteristics that are shared by whoever occupies the Position, which seems to suggest an interpretation of Position as some sort of Universal.

To solve this issue, we propose to interpret the Position element as a Social Role which can only be played by a Person (Human Agent). In this case, the occupies meta-association between Person and Position is interpreted as Instantiation of the Social Role by the Agent. Under this interpretation of the Position element, the problem of weak supplementation is eliminated, because a Position is no longer interpreted as an ontological entity formed by functional parts. (And any Institutional Agent would then be composed of at least two agents.)

The is composed of meta-association between Organizational Unit and Position can be interpreted as capturing the functional composition of an organization unit and one or more positions. At the instance level, this represents a whole-part relationship between the Institutional Agent and whoever instantiates the Social Role (ultimately a Human Agent). This whole-part relation is called componentOf [30] or Component/Functional Complex [71].

\subsection{Position Type}

The Position Type element is a notational element in ARIS. This means that it is introduced a posteriori (through a notational filter in the toolset) and thus must be considered as a simple specialization of an existing metaclass (in this case an Organizational Unit Type) with no further meta-attributes and meta-associations. This is understandable given the ARIS definition of Position as an Organizational Unit. A consequence of this choice in the metamodel is that there is an is of type meta-association between Position and Organizational Unit Type which we believe is intended to be used only for Organizational Unit Types that are specialized into Position Types. We assume here that this is the intention of the tool implementers, and analyze only the relation between Position and Position Type (and not just an arbitrary Organizational Unit Type).

Under the suggested interpretation of Position as a Social Role we may interpret a Position Type as: a $\underline{\text { Social Role Mixin or a High Order Universal. }}$

In the first case (i), the is of type meta-association between Position and Position Type would be interpreted as subsumption of the Social Role (represented by the Position element) by the Social Role Mixin (represented by the Position Type element). An example of this case occurs if we model the Positions "Sales Department Manager", "Engineering Department Manager", "Accounting Department Manager" related to the Position Type "Manager" through is of type.

Under the second interpretation (Position Type as High Order Universal), a Position Type characterizes a multitude of Social Roles (universals). In this case the is of type meta-association between Position and Position Type would be interpreted as instantiation of the Higher-Order Universal. An example of this case occurs if we model the Positions "Sales Department Manager", "Engineering Department Manager", "Accounting Department Manager" related to the Position Type "Type of Manager" through is of type. 
The particular interpretation here depends on the intention of the modeler; we have found plausible examples in usage to suggest either interpretation. We conclude that a revision of the language would be necessary to distinguish between these alternative interpretations, as they seem to be useful on their own. We suggest that the construct be used to denote a Higher Order Universal, since Social Roles can be modeled with the Position construct.

Table 1 shows a summary of our analysis revealing the possible ontological interpretations for organizational unit, organizational unit type, position and position type, a diagnosis of language issues, and a suggested ontological interpretation and language recommendations to avoid the issues identified.

Table 1 Suggested ontological interpretation and language recommendations for the organizational unit, organizational unit type, position and position type

\begin{tabular}{|c|l|l|l|}
\hline ARIS & \multicolumn{1}{|c|}{$\begin{array}{c}\text { Possible ontological } \\
\text { interpretation (in UFO) }\end{array}$} & \multicolumn{1}{c|}{ Diagnosis } & $\begin{array}{c}\text { Suggested ontological interpretation (in UFO) and } \\
\text { language recommendation }\end{array}$ \\
\hline $\begin{array}{c}\text { Organizational } \\
\text { Unit }\end{array}$ & Institutional Agent & - & $\underline{\text { Institutional Agent }}$ \\
\hline $\begin{array}{c}\text { Organizational } \\
\text { Unit Type }\end{array}$ & $\underline{\text { Institutional Agent Universal }}$ & - & $\underline{\text { Institutional Agent Universal }}$ \\
\hline \multirow{3}{*}{$\begin{array}{c}\text { Position } \\
\text { Position Type }\end{array}$} & $\begin{array}{l}\text { Social Role which can only be } \\
\text { played by a Person (ultimately } \\
\text { a Human Agent) }\end{array}$ & Semantic Overload- & $\begin{array}{l}\text { Social Role which can only be played by a Person } \\
\text { (avoiding semantic overload and observing the weak } \\
\text { supplementation principle) }\end{array}$ \\
\cline { 2 - 4 } & $\underline{\text { Institutional Agent Universal }}$ & Social Role & $\begin{array}{l}\text { Higher Order Universal whose instances are Social } \\
\text { Roles (avoiding semantic overload and construct } \\
\text { redundancy considering the suggested interpretation } \\
\text { for Position) }\end{array}$ \\
\hline
\end{tabular}

\subsection{Person}

According to the on-line documentation of the ARIS toolset, the Person element represents " $a$ person who may be assigned to an Organizational Unit and Position". This is captured in the metamodel by the belongs to meta-association between Person and Organizational Unit and by the occupies meta-association between Person and Position.

There are two alternative interpretations here: in the first interpretation, the instances of the Person metaclass represent a particular Human Agent. Under this interpretation, the belongs to meta-association between Person and Organizational Unit can be interpreted as a part-whole relationship (Human Agent is componentOf Institutional Agent). The occupies meta-association between Person and Position can be interpreted as instantiation (in which case the Human Agent instantiates contingently the Social Role universal).

An alternative interpretation is that all instances of the Person metaclass represent Human Agents which instantiate an implicit "Employee" Social Role universal (an interpretation in line with the former name of the Person metaclass: Employee). All Positions in a model would be specializations of this implicit Social Role universal. This interpretation may be undesirable because it would mean that Person (in the ARIS sense) cannot be used to model (external) human stakeholders, relevant to the enterprise model at hand but not an employee of any organization being considered. Thus, in the presence of ambiguity, we recommend the adoption of the first interpretation (Person as a Human Agent) to maximize the applicability of the language ${ }^{3}$.

\subsection{Group}

According to the on-line documentation of ARIS Toolset, the Group element represents a set of employees who are working together for a specific period of time. This suggests that Group represents a whole in a whole-part relation with individuals. We believe it is possible to interpret the Group element as either a

\footnotetext{
${ }^{3}$ Please observe that this recommendation requires a particular interpretation of "may be assigned" in the quoted ARIS definition, denoting possibility while not implying an obligation or commitment to be assigned to an Organizational Unit and Position (which would characterize a person as an employee).
} 
Collective Social Agent or as an Institutional Agent. The difference in interpretation will depend on the use of Group element and the associations a Group establishes as a whole.

There are two meta-associations in the metamodel that seem to capture the whole-part relations in which a Group may be involved: is composed of (Positions) and has member (Persons).

If a Group is related to Positions (Social Role) then we should interpret Group as an Institutional Agent. The is composed of meta-association between Group and Position can be interpreted as capturing the functional composition of a group and one or more positions. At the instance level, this represents a whole-part relationship between the Institutional Agent and whoever instantiates the Social Role (ultimately a Human Agent) (as we have discussed earlier this is a whole-part relation called componentOf [30] or Component/Functional Complex [71].) An example of this situation occurs when we model a parliamentary inquiry committee in which some of the congressmen play different roles, for example, if one of them is the chairman of the committee. This interpretation of Group renders this concept identical to the concept of Organizational Unit, representing a case of construct redundancy in the language.

However, if a Group is used exclusively to capture a uniform grouping of Persons with no specific roles (i.e., if only has member is used), then we should interpret the Group metaclass as representing a Collective Social Agent. In this case, the has member association should be interpreted as a whole-part relationship called memberOf [30] or Member/Collection [71]. An example of this situation occurs when we model a parliamentary inquiry committee in which all congressmen play the same role. The distinction in interpretation is important given the implications of the different kinds of whole-part relations as discussed in [30]. In particular, memberOf relations are never transitive while transitivity among componentOf relations only holds in certain contexts.

A question that still has to be considered in this last interpretation of Group as a Collective Social Agent is whether the Group represents a collective with an extensional or non-extensional principle of identity. In the case of an extensional principle of identity a change in the composition of the Group would change the Group itself. The nature of the principle of identity cannot be specified in the ARIS organizational language.

A further case of construct deficit can be identified here: there is no notion of Collective Social Agent (Group or other concept) that can be applied to group Institutional Agents (Organizational Units) in ARIS. This would be desirable to capture collectives such as enterprise consortia.

\subsection{Person Type}

According to the on-line documentation of the ARIS Toolset, the Person Type element "is a typification of a set of people who have the same features: responsibilities, rights, obligations, among others". This definition strongly suggests that Person Type should be interpreted as some specific kind of Universal.

Considering the interpretation of Person as Human Agent and the existence of the is of type meta-association between Person and Person Type it could be possible to interpret the Person Type element as a Human Agent Universal. In this case, is of type should be interpreted as necessary instantiation of the rigid Human Agent Universal represented by the Person Type.

However, semantic overload in the language is revealed when we extend the analysis of Person Type to include all performs meta-associations in which this metaclass participates, namely: the performs metaassociations between Position and Person Type; Person and Person Type; Organizational Unit and Person Type; Organizational Unit Type and Person Type; Group and Person Type; and finally, Location and Person Type. In other words, all metaclasses of the organizational model may perform an ARIS Person Type. (Which is quite surprising given the label "Person Type", which seems to suggest that only "Persons" are characterized by a Person Type.)

To avoid an interpretation in which the performs meta-associations represent an unusually abstract relation that can hold between entities of largely different natures (e.g, capturing both relations between universals and between universals and individuals), we split these meta-associations into two different sets: the performs meta-associations between (i) instance-level elements (Person, Organizational Unit and Group) and Person Type; and (ii) type-level elements (Position, Organizational Unit Type) and Person Type ${ }^{4}$.

\footnotetext{
${ }^{4}$ We defer interpretations involving Location, since we have not discussed the interpretation of that element yet.
} 
Considering the performs meta-associations between instance-level elements (Person, Organizational Unit and Group) and Person Type (i), the most general interpretation for the performs relation is contingent instantiation of the Social Role Mixin represented by the Person Type. This interpretation of Person Type is required when it is used as a universal that captures general contingent characteristics of elements of different natures, in this case, at least, Human Agents (Persons), Institutional Agents (Organizational Units) and Collective Social Agents (Groups). However, it is possible that a particular enterprise model employs Person Type in particular settings to capture general contingent characteristics of elements of specific natures, in which case it is related to either Human Agents (Persons), Institutional Agents (Organizational Units) or Collective Social Agents (Groups). In that case, Person Type should be interpreted as a Social Role. This second interpretation reveals a case of construct redundancy in the language: what would distinguish a Position from a Person Type that is only applied to characterize the contingent behavior of Human Agents (Persons)?

Assuming these two context-dependent interpretations for Person Type (Social Role Mixin or Social Role), we proceed by considering the performs relation between type-level elements (Position, Organizational Unit Type) and Person Type (ii). The interpretations in this case are also far from trivial, given the flexibility in usage of the elements of the language.

If the relation applies necessarily to all instances of a Position, then we conclude that it should be interpreted as a specialization between the Social Role represented by the Position and the Social Role (Mixin) represented by the Person Type. For example, this occurs if we model that the Position "Senator" (a Social Role) performs the Person Type "Member of Congress" (a Social Role that subsumes the specialized "Senator" Social Role).

However, if it applies contingently to those occupying a Position, then the relation seems to imply that both the Social Role represented by the Position and the Social Role represented by the Person Type share a sortal supertype (a Kind) and further that there is an intersection in the set of instances of the two Social Roles. An example of this situation occurs when we model that the Position "Senator" (a Social Role) may contingently perform the "Member of Parliamentary Committee" Person Type (a Social Role). These Social Roles are nondisjoint specializations of some Human Agent Universal: while some senators may play the role of "Member of Parliamentary Committee" there are "Members of Parliamentary Committee" which are not "Senators" (e.g., "Deputies") and there are "Senators" which are not "Members of Parliamentary Committee". Please note again a case of construct redundancy, since the Social Role "Member of Parliamentary Committee" could be modeled as a Position or a Person Type with the same semantics. When Person Type is interpreted as a Social Role Mixin, then there is an implicit specialization of this Social Role Mixin which shares a sortal supertype (a Kind) with the Social Role represented by the Position. Again, there is an intersection in the set of instances of the two Social Roles.

When the relation applies contingently to the instances of an Organizational Unit Type (Institutional Agent Universal) then there is an unnamed Social Role that specializes the Institutional Agent Universal and the Social Role (or Social Role Mixin) represented by the Person Type.

If the relation applies necessarily to the instances of an Organizational Unit Type, this would require a different interpretation of Person Type. This is because Person Type can no longer represent a Social Role Mixin, which is, by definition, anti-rigid. In this case, an alternative would be a (Social) Mixin, which is nonrigid and represents properties that are essential to some of its instances and accidental to others [30]. An example which illustrates this situation occurs if we model that an Organization Unit Type "Purchase Department" performs a Person Type "Shopping Client" necessarily and that, at the same time, an Organizational Unit Type "IT Department" may perform the same Person Type contingently (whenever the "IT Department" bypasses the "Purchase Department" and purchases equipment directly.)

In any case, the language lacks expressiveness to distinguish whether the Person Type applies necessarily or contingently to whatever is said to perform the Person Type.

Finally, in all interpretations we consider the is generalization of meta-association between Person Types captures the well-known specialization relation between universals. 
Table 2 shows a summary of our analysis revealing the possible ontological interpretations for person, group and person type, a diagnosis of language issues, and a suggested ontological interpretation and language recommendations to avoid the issues identified.

Table 2 Suggested ontological interpretation and language recommendations for person, group and person type

\begin{tabular}{|c|c|c|c|}
\hline ARIS & $\begin{array}{l}\text { Possible ontological } \\
\text { interpretations (in UFO) }\end{array}$ & Diagnosis & $\begin{array}{l}\text { Suggested ontological interpretation (in UFO) and } \\
\text { language recommendation }\end{array}$ \\
\hline \multirow[b]{2}{*}{ Person } & Human Agent & \multirow[b]{2}{*}{ Semantic Overload } & \multirow[b]{2}{*}{$\begin{array}{l}\text { Human Agent } \\
\text { ensuring broad applicability of the construct) }\end{array}$} \\
\hline & $\begin{array}{llr}\text { Human } & \text { Agent } & \text { instance of } \\
\text { implicit } & \text { "employee" } & \text { Social } \\
\text { Role } & & \\
\end{array}$ & & \\
\hline \multirow{2}{*}{ Group } & $\begin{array}{l}\text { Collective Social Agent for } \\
\text { Human Agents }\end{array}$ & \multirow{2}{*}{ Semantic Overload } & \multirow{2}{*}{$\begin{array}{l}\text { Collective Social Agent for Human Agents (avoiding } \\
\text { semantic overload and construct redundancy } \\
\text { considering the suggested interpretation for } \\
\text { Organization Unit) }\end{array}$} \\
\hline & $\underline{\text { Institutional Agent }}$ & & \\
\hline \multirow{3}{*}{ Person Type } & Social Role Mixin & \multirow{3}{*}{ Semantic Overload } & \multirow{3}{*}{$\begin{array}{l}\text { Social Mixin (a non-rigid mixin) (avoiding semantic } \\
\text { overload and construct redundancy considering the } \\
\text { suggested interpretation for Position, while preserving } \\
\text { the flexibility in construct use.) }\end{array}$} \\
\hline & $\underline{\text { Social Role }}$ & & \\
\hline & $\underline{\text { Social Mixin (non-rigid mixin) }}$ & & \\
\hline
\end{tabular}

\subsection{Position Description}

Similarly to Position Type, Position Description is a notational element in ARIS. Position Description must be considered as a simple specialization of Person Type with no further meta-attributes and meta-associations. We assume that the intention of the tool implementers is to distinguish the case in which a Person Type is used exclusively to characterize Positions (i.e., when only Positions are related to this Person Type through the performs relation.)

As discussed in the previous section, when Person Type is used to characterize Positions only, it can be interpreted as a Social Role. In this case, there would be no ontological distinction between Position Descriptions and Positions (both Social Roles) characterizing a possible case of construct excess.

\subsection{Location}

According to the on-line documentation of the ARIS Toolset the Location element represents the geographic location of persons, organizational units, positions and groups. In line with this documentation, we interpret the Location element as representing a Quale that is a member of a Quality Structure to capture geographical notions. The various meta-associations called is located at and at location are used to associate an implicit Quality of organizational elements (geographical location). For example, through this meta-association it is possible to model that "UFES" (Organizational Unit) is located in "Vitória" (Location). The Location "Vitória" represents a Quale that is a member of a Quality Structure that is a set with all municipalities in Brazil.

The metamodel also includes an encompasses meta-association, which allows us to say that a certain location is contained within another location. For example, we can model that the state of Espírito Santo (Location) encompasses the city of Vitória (Location). The encompass relation between Locations should be interpreted as a formal relation that is part of the definition of the Quality Structure. It relates two Quales of the structure, such that the modeler can define a particular Quality Structure suitable to capture the geographical notions for the enterprise architecture at hand.

To proceed with the analysis, we must also consider the performs meta-association. This association seems to suggest that Location is not only establishing geographical notions but is also used as some sort of Organizational Unit. This would constitute a case of semantic overload in the language with very diverging concepts collapsed into the Location element. For example, we could be talking about "Vitória" as an Institutional Agent (in this case the political notion of municipality, which includes a Position of "Mayor") or as a Quale (encompassing all the geographical coordinates within the boundaries of the municipality). In this example, the notions seem to coincide or to have different facets. However, there are many geographical locations which have no organizational counterpart, such as "Room 101 of the Computer Science Building" or 
"Annex B of the Brazilian Senate Building". These example locations would not possibly perform an intentional role in a business process.

The is organization manager for meta-association among Person, Position and Location represents that a location can manage a person or position. However, this interpretation suggests that the Location element, again, is being used as an organizational unit. For example, Paulo is organization manager for Vitória (Organizational Unit). Thus, we have the same semantic overload problem that occurred in performs metaassociation. Due to the semantic overload problem it is suggested remove the following meta-associatons that occurs between Location and other elements: is organization manager for and performs.

We conclude that the language would be clearer and would have the same expressiveness if the performs meta-association would be suppressed. Whenever necessary, an Organizational Unit should be defined and related to the corresponding Location through at location.

\subsection{Other Relations}

We have restricted our analysis to certain meta-associations representing instantiation, whole-part relations and specialization. The metamodel also includes a number of meta-associations to enable a modeler to capture notions such as responsibility, cooperation, conflicts, management hierarchy, etc. (These are called substitutes for, is responsible for, is assigned to, is in conflict with, is organizational manager for, cooperates with, is technical superior to, is disciplinary superior to, can be technical superior and is managed by and have been omitted from Figure 2.)

Although certain intuitive notions can be inferred from the names of the meta-associations, a precise interpretation for these elements is elusive. Furthermore, the interpretation of these may be highly enterprisedependent or domain-dependent (e.g., consider the different implications of disciplinary superiority in a military setting or in a civilian enterprise, or yet the various kinds of accountability and responsibility constructions in different countries or even different states in the same country.) Therefore, we opt to state only that these represent social relations defined by particular normative descriptions in the context in which they apply. If required, the semantics of these relations could be explored in particular settings. The UFO notions of intentions (goals), intentional events (actions), social commitments and claims, open and closed delegation, would be instrumental in providing an account for several of these relations such as, e.g., is in conflict with, cooperates with and is managed by.

While we focused here on the organizational chart, the modeling elements of the organizational Model are used in several other ARIS Models, for example, the Position, Organizational Unit and Person Type are used in Business Process models (EPC) and Function Allocation Diagram (FAD). Please refer to [54] for an ontological analysis of EPCs using the same foundations discussed here; that work proposes an ontological account for the carries out meta-association between Function and the organizational elements discussed here (which explains how organizational elements take part in organizational activities).

\subsection{Summary}

Table 3 shows a summary of our analysis revealing the possible ontological interpretations we have identified, a diagnosis of language issues, and a suggested ontological interpretation and language recommendations to avoid the issues identified.

Table 3 - Suggested ontological interpretation and language recommendations for the organizational constructs

\begin{tabular}{|c|c|c|c|}
\hline ARIS & $\begin{array}{l}\text { Possible ontological } \\
\text { interpretations (in UFO) }\end{array}$ & Diagnosis & $\begin{array}{l}\text { Suggested ontological interpretation (in UFO) and } \\
\text { language recommendation }\end{array}$ \\
\hline $\begin{array}{l}\text { Organizational } \\
\text { Unit }\end{array}$ & $\underline{\text { Institutional Agent }}$ & - & $\underline{\text { Institutional Agent }}$ \\
\hline $\begin{array}{l}\text { Organizational } \\
\text { Unit Type }\end{array}$ & Institutional Agent Universal & - & Institutional Agent Universal \\
\hline \multirow[t]{2}{*}{ Position } & $\begin{array}{l}\text { Social Role which can only be } \\
\text { played by a Person (ultimately } \\
\text { a Human Agent) }\end{array}$ & \multirow[t]{2}{*}{ Semantic Overload } & \multirow{2}{*}{$\begin{array}{l}\text { Social Role which can only be played by a Person } \\
\text { (avoiding semantic overload and observing the weak } \\
\text { supplementation principle) }\end{array}$} \\
\hline & Institutional Agent Universal & & \\
\hline \multirow{2}{*}{ Position Type } & $\underline{\text { Social Role }}$ & \multirow{2}{*}{ Semantic Overload } & \multirow{2}{*}{$\begin{array}{l}\text { Higher Order Universal whose instances are } \underline{\text { Social }} \\
\text { Roles (avoiding semantic overload and construct }\end{array}$} \\
\hline & Higher Order Universal & & \\
\hline
\end{tabular}




\begin{tabular}{|c|c|c|c|}
\hline & & & $\begin{array}{l}\text { redundancy considering the suggested interpretation for } \\
\text { Position) }\end{array}$ \\
\hline \multirow[b]{2}{*}{ Person } & Human Agent & \multirow[b]{2}{*}{ Semantic Overload } & \multirow[b]{2}{*}{$\frac{\text { Human Agent }}{\text { ensuring broad applicability of the construct) }}$} \\
\hline & 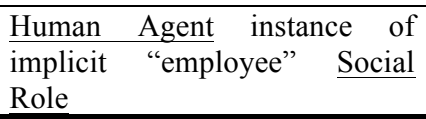 & & \\
\hline \multirow{3}{*}{ Person Type } & $\underline{\text { Social Role Mixin }}$ & \multirow{3}{*}{ Semantic Overload } & \multirow{3}{*}{$\begin{array}{l}\text { Social Mixin (a non-rigid mixin) (avoiding semantic } \\
\text { overload and construct redundancy considering the } \\
\text { suggested interpretation for Position, while preserving } \\
\text { the flexibility in construct use.) }\end{array}$} \\
\hline & $\underline{\text { Social Role }}$ & & \\
\hline & $\underline{\text { Social Mixin (non-rigid mixin) }}$ & & \\
\hline $\begin{array}{l}\text { Position } \\
\text { Description }\end{array}$ & $\underline{\text { Social Role }}$ & $\begin{array}{l}\text { Construct } \\
\text { Redundancy }\end{array}$ & $\begin{array}{l}\text { Elimination of the construct to avoid redundancy } \\
\text { considering the suggested interpretation of Position }\end{array}$ \\
\hline \multirow[b]{2}{*}{ Group } & $\begin{array}{ll}\text { Collective Social Agent for } \\
\text { Human Agents }\end{array}$ & \multirow[b]{2}{*}{ Semantic Overload } & \multirow{2}{*}{$\begin{array}{l}\text { Collective Social Agent (avoiding semantic overload } \\
\text { and construct redundancy considering the suggested } \\
\text { interpretation for Organization Unit). Language cannot } \\
\text { differential between extensional and intensional } \\
\text { identity criteria for groups. }\end{array}$} \\
\hline & $\underline{\text { Institutional Agent }}$ & & \\
\hline- & $\begin{array}{l}\text { Collective Social Agent when } \\
\text { applied to Institutional Agents }\end{array}$ & Construct Deficit & $\begin{array}{l}\text { Language revision would be required to incorporate } \\
\text { elements to express this particular category of } \\
\text { collective social agents, which enable the language to } \\
\text { model enterprise federations or consortia. }\end{array}$ \\
\hline \multirow[b]{2}{*}{ Location } & Quale & \multirow[b]{2}{*}{ Semantic Overload } & \multirow{2}{*}{$\begin{array}{l}\text { Quale (avoiding semantic overload and construct } \\
\text { redundancy considering the suggested interpretation for } \\
\text { Organization Unit) } \\
\text { Elimination of the performs meta-association. }\end{array}$} \\
\hline & $\begin{array}{l}\text { Institutional Agent (when } \\
\text { related through the performs } \\
\text { meta-association) }\end{array}$ & & \\
\hline
\end{tabular}

\subsection{A Well-Founded Dialect of the ARIS Organizational Modeling Language}

Figure 7 presents the metamodel of a dialect of the organizational modeling language following the recommendations for the various constructs.

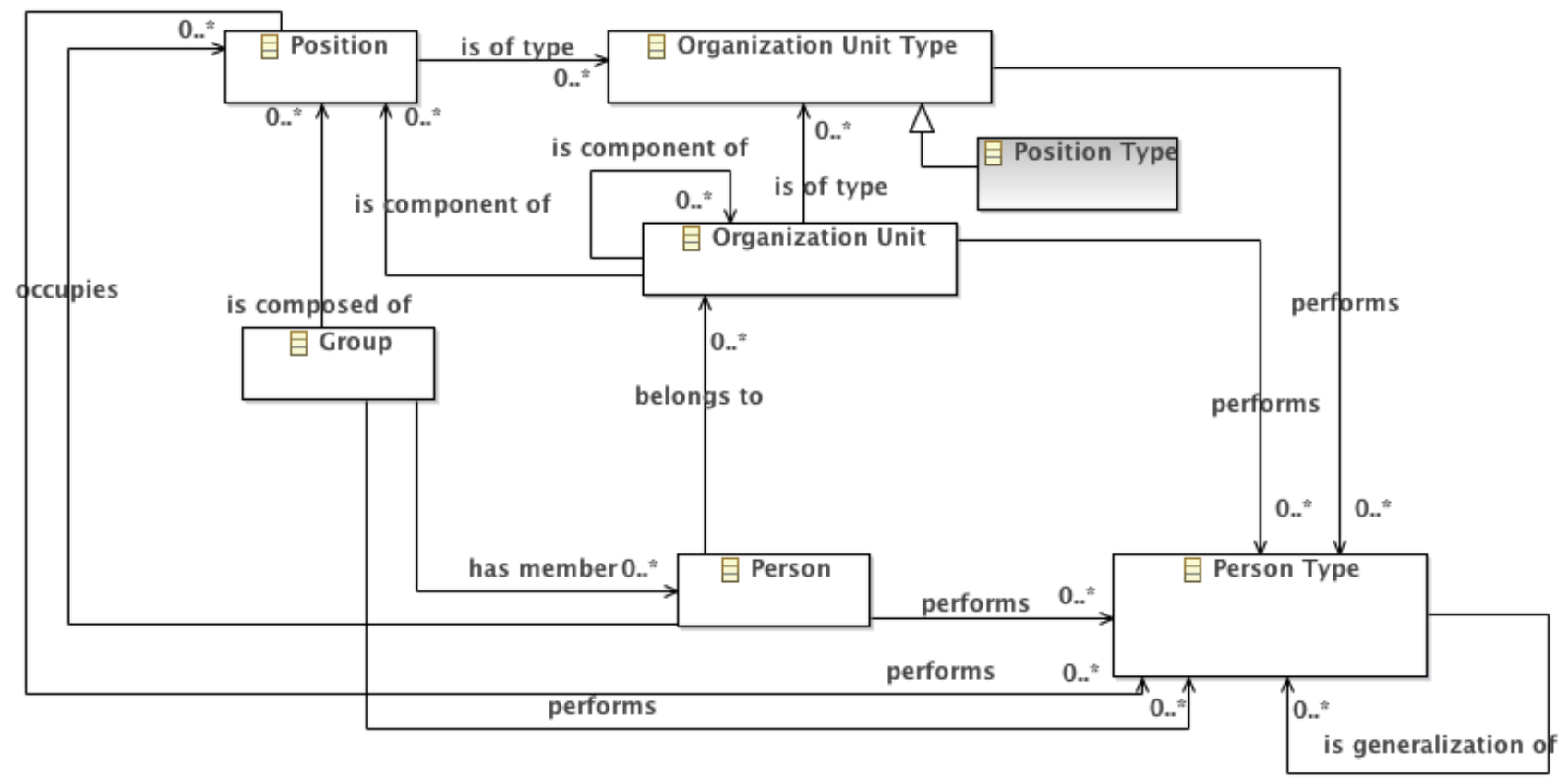

\section{Figure 7 - Metamodel of a well-founded lightweight extension to the organizational language}

Note that we have restricted ourselves to a lightweight extension of ARIS, removing ambiguous or meaningless relations and construct excess. This would allow this extension to be implemented through a "notational filter" in the ARIS toolset and through conventions to be followed by modelers. At the same time, the proposed dialect would not break the consistency with the remainder of the ARIS framework, since several other models, such as Event-driven Process Chains (EPCs) and Function Allocation Diagrams (FADs) have many relations with the organizational models. 
We have removed the "Position Description" metaclass, which has been considered a case of construct excess. Only the metaassociations whose interpretations are clear have been preserved. Their interpretation is provided in Table 4.

Table 4 - Suggested ontological interpretation and language recommendations for the organizational constructs

\begin{tabular}{|c|c|}
\hline ARIS & Suggested ontological interpretation (in UFO) \\
\hline Position is of type Position Type & Instantiation of a Higher Order Universal whose instances are Social Roles \\
\hline Position performs Person Type & Specialization of a Social Mixin by a Social Role \\
\hline $\begin{array}{l}\text { Organizational Unit is of type Organizational Unit } \\
\text { Type }\end{array}$ & Instantiation of an Institutional Agent Universal \\
\hline $\begin{array}{l}\text { Organizational Unit is component of Organizational } \\
\text { Unit }\end{array}$ & A componentOf whole-part relation between Institutional Agents. \\
\hline Organizational Unit is composed of Position & $\begin{array}{l}\text { Represents at type level the componentOf whole-part relation between the } \\
\text { Institutional Agent (represented by the Organizational Unit) and instances of } \\
\text { the Social Role (represented by the Position). }\end{array}$ \\
\hline Organizational Unit performs Person Type & Instantiation of a Social Mixin \\
\hline Group has member Person & $\begin{array}{l}\text { A memberOf whole-part relation between the Collective Social Agent } \\
\text { (represented by the Group) and a Human Agent. }\end{array}$ \\
\hline Group is composed of Position & $\begin{array}{l}\text { Represents at type level the memberOf whole-part relation between the } \\
\text { Collective Social Agent (represented by the Group) and instances of the } \\
\text { Social Role (represented by the Position). }\end{array}$ \\
\hline Person performs Person Type & Instantiation of a Social Mixin \\
\hline Person occupies Position & Instantiation of a Social Role \\
\hline Person belongs to Organizational Unit & $\begin{array}{l}\text { A componentOf whole-part relation between a Human Agent and an } \\
\text { Institutional Agent. }\end{array}$ \\
\hline Person Type is generalization of Person Type & Subsumption \\
\hline Organizational Unity Type performs Person Type & Specialization of a Social Mixin by an Institutional Agent Universal \\
\hline Location encompasses Location & Formal relation that is part of the definition of the location Quality Structure \\
\hline Organizational Unit at location Location & $\begin{array}{l}\text { Quality of organizational elements (geographical location). In the case of a } \\
\text { distributed Organizational Unit, multiple locations can be associated with the } \\
\text { Organizational Unit. }\end{array}$ \\
\hline Position at location Location & $\begin{array}{l}\text { Quality of organizational elements (geographical location). Should be } \\
\text { interpreted as indicating the location of the organizational unit in which the } \\
\text { Position is defined (thus a derived association, considering Organizational } \\
\text { Unit at location Location and Organizational Unit is composed of Position). }\end{array}$ \\
\hline Person at location Location & Quality of a Human Agent (geographical location). \\
\hline Group at location Location & $\begin{array}{l}\text { Quality of organizational elements (geographical location). Should be } \\
\text { interpreted as all the locations of elements of the group (thus a derived } \\
\text { association, considering Person at Location and Group has member Person). }\end{array}$ \\
\hline
\end{tabular}

We consider that the is of type metaassociation between Position and Organizational Unit Type should be constrained such that it can only be used to relate to instances of Position Type. Similarly, the performs association should not be used to relate instances of Position Type and Person Type. In a heavy-weight extension to the language, the specialization relation between Position Type and Organizational Unit Type should be subtracted from the metamodel, and the is of type metaassociation should relate directly Position and Position Type.

In the proposed lightweight extension, any subsumption hierarchies for Positions and Organizational Unit Types must be encoded as a subsumption hierarchy for Person Types, employing the is generalization of metaassociation. Positions and Organizational Unit Types are "leaf-only" classes in a lightweight extension as no metaassociations may be added. A heavyweight extension would be required in order to support a subsumption hierarchy for Positions, Organizational Unit Types and Position Types adding is generalization of metaassociations for these metaclasses. Although multiple interpretations for the performs metaassociations have been identified in our analysis when relating Position or Organizational Unit and Person Type, we settle here for one of those interpretations for the sake of proposing a lightweight extension to the language. (We take the interpretation that the relation applies necessarily to the instances of Position and Organizational Unit Type.) Again, a heavyweight extension would also allow one to express that performs may apply contingently to the instances of Position and Organizational Unit Type. 
We consider that the extensional and intentional criteria for Collective Social Agents (represented by Groups) could be implemented by adding two notational elements specializing the Group metaclass. This would provide a precise interpretation for the identity criterion of a Group when required.

Finally, a heavyweight extension of the language would be required in order to support Collective Social Agents when containing Institutional Agents as members, in order to support Groups of Organizational Units as we have discussed in section 5.4.

\section{DISCUSSION AND RELATED WORK}

The study which is most closely related to our work was conducted by Green and Rosemann and presented in [24], [25]. Green and Rosemann discuss an ontological analysis of ARIS models based on the BWW ontology ([67], [68] based on the work of Mario Bunge [9]). Similar to our work, Green and Rosemann also conclude that ARIS provides an extensive number of symbols for modelers to choose from that overlap in terms of their real world meanings.

Differently from our work, Green and Rosemann have relied on the metamodels in Scheer's original proposal [56]. As we have discussed in [55], the language metamodel in the ARIS Toolset is significantly different from the metamodels in Scheer's original proposal [56]. As a consequence, the approaches based on Scheer's metamodels do not consider the characteristics of the modeling language as actually implemented and employed in enterprises worldwide.

Further, the analysis by Green and Rosemann is very general, mostly with the purpose of analyzing coverage of BWW concepts by ARIS. Instead, we have performed a thorough analysis of the individual elements and their relations.

A number of studies by Zur Muehlen et al. have addressed the coverage of languages with respect to a reference ontology (again the BWW ontology), under the terms "representational analysis" and more specifically, "overlap analysis" (see, e.g., [72], [73]). Similar efforts have been pursued by Recker et al. [52], to apply "representation analysis" in the comparison of business process modeling techniques. While using a reference ontology to evaluate enterprise modeling languages, that line of work is significantly different from ours in the sense that it does not aim at clarifying language semantics. Instead, that line of work focuses on initial diagnosis and language comparison. In this respect, one could characterize these related efforts as ontological analysis in breadth, while we pursue in this paper ontological analysis in depth. We have shown that proposed interpretations for the various constructs of the organizational language depends on considering the various relations in the language's metamodel, an endeavor which cannot be tackled by the approach employed in ontological analysis in breadth.

Other significant differences between our approaches and those based on BWW arise from the choices in the foundational ontologies employed and the mapping choices employed in the analysis. As we have observed in [54], UFO, but not the BWW ontology, makes an explicit distinction between unintentional events and (intentional) actions. To understand organizations, social roles, business processes and notions such as services as social phenomena, the notions of goals and commitment are of fundamental importance [16]. This requirement places an approach founded on an ontology in which social reality is treated in an explicit manner in clear advantage.

We believe that our work has important implications for the ontological account of the "who" column of the Zachman framework, and is exemplified here in the ARIS organizational language. The question-based column structure of the framework (i.e., the why, how, what, who, where, when) was actually inspired in the question-based organization structure of Aristotle's first ten-categories ontology (i.e., substance - what?, quantity - how much?, quality - what kind?, place - where? time - how much?). This is according to the ontologist John Sowa, co-author of the Zachman framework proposal in [62] (personal communication). However, a fuller development of an ontological account of the framework itself is yet to be developed. The semantic foundation employed here may be applied in such future efforts concerning the "who" column of several enterprise architecture frameworks and standards. We have ourselves recently performed the analysis of the "community" aspects of the RM-ODP language [53] using UFO, leading to a number of recommendations for standardization as reported in [2]. 
We anticipate that the technique could be employed for several other approaches such as ArchiMate [65], TOGAF [66], DoDAF [15] and MODAF [47]. Some initial findings in this respect were reported in [1], where we have analyzed some of these techniques including an initial ontological evaluation of the ARIS role-related concepts. These concepts are discussed here in more depth, although the initial work allows one to position and contrast ARIS with other enterprise modeling approaches. A thorough analysis of the various frameworks would be a natural extension of our work and could lead to recommendations for organizational structure standardization, which is much needed in the face of the fragmentation of the various languages.

Additional examples of the application of UFO in the analysis and re-design of other modeling languages can be found in [36], which addresses the semantics of AORML, an agent-oriented modeling language, in [5, 6] in which the language is used to analyze a number of disciplines of the ITIL IT Governance proposal, in [34] in which UFO is used to analyze several organization and discrete event simulation languages and environments, including Brahms [60] and BPMN, and in other several works [21, 40, 42, 43].

\section{CONCLUSIONS AND FUTURE WORK}

The ontological analysis presented in this paper provides a better understanding of the organizational modeling elements in ARIS with the support of a foundational ontology. An immediate benefit of our ontological analysis is related with the development of organizational models with well-defined real-world semantics. We defend that a clear semantic account of the concepts underlying enterprise modeling languages is key for enterprise modeling to mature as a discipline.

Since we are concerned here with organizational phenomena, the reference ontology we adopt for evaluation is a foundational ontology that addresses social reality, including thus an account for social roles, social relations, intentionality and agency.

The ontological analysis we have performed has allowed us to reveal problems of usage of certain modeling elements in organizational models. There are several issues of semantic overload, construct redundancy and construct deficit. ARIS has a rich set of elements to describe organizational structure at instance-level and type-level and a large number of relations between the metaclasses for the organizational structure domain. The problems encountered when analyzing the relations of certain metaclasses suggest a thorough language revision would be necessary to ensure that the language semantics is free from dispute. Further, we should note that defining a semantics a posteriori requires speculating the original intent of the language designers. Naturally, this implies that other plausible interpretations may be possible. The availability of an ontological interpretation for the language addressed here enables us to contrast alternatives for the semantics and would enable others to disagree and question the interpretation having a precise and explicit ground for that.

The analysis has allowed us to justify informal comments in the ARIS literature with respect to the elements of the organizational model. For example, Davis observes when discussing the organizational elements that "it is best to severely restrict the objects available, otherwise people interpret them in different ways" [13]. Thus, our analysis corroborates this intuition and provides a systematic account for it.

It is important to note that the main role of the ontological analysis has been to provide us with a rigorous framework to analyze the ARIS Method. In this sense, ontological analysis should be seen as a tool for hypothesis formulation, and the recommendations that we have identified here should be considered as hypothesis subject to further examination. In particular, one should consider the pragmatic impact of amendments on the language and its users. Further, we do not intend to suggest that the terminology used in this paper should replace the terminology currently used in the language, and we do not intend to imply that the UFO conceptualization should be exposed directly to users of the tool.

The interpretation discussed here is complementary to our previous work on a semantic foundation for process modeling in the ARIS method, in which we have addressed the process-related concepts of Event-driven Process Chains (EPCs) [54] and to our previous work on the ARIS objective diagram [10]. Our next steps with respect to the interpretation of the ARIS method will focus on an ontological analysis of the ARIS notations for capturing the detailing of activities (the Function Allocation Diagram - FAD). Our long-term objective is the definition of a well-founded subset of the ARIS language for enterprise modeling, accommodating the improvements that arise from ontological analysis. In tandem, we will pursue the ontological analysis of other approaches which address organizational structure modeling (such as ArchiMate 
[65], TOGAF [66], DoDAF [15] and MODAF [47]). This should ultimately lead to recommendations for organizational structure language interoperation and standardization.

\section{References}

[1] Almeida, J. P. A., Guizzardi, G., and Santos Jr., P. S. Applying and Extending a Semantic Foundation for Role-Related Concepts in Enterprise Modeling, Enterprise Information Systems, v3, pp. 253-277 .2009.

[2] Almeida, J. P. A., Guizzardi, G., An ontological analysis of the notion of community in the RM-ODP enterprise language, Computer Standards \& Interfaces, Elsevier, 2012, doi:10.1016/j.csi.2012.01.007.

[3] Arpini. R.H. and Almeida, J.P.A., On the Support for the Assignment of Active Structure and Behavior in Enterprise Modeling Approaches, Proceedings of the $27^{\text {th }}$ Annual ACM Symposium on Applied Computing, ACM, 2012, pp. 1686-1693.

[4] Azevedo, C. L. B., et al. An Ontology-Based Semantics for the Motivation Extension to ArchiMate, Proceedings of the 15th IEE International EDOC Conference (EDOC), IEEE Computer Society Press, 2011.

[5] Baioco, G. et al. IT service management and governance modeling an ITSM Configuration process: A foundational ontology approach, IFIP/IEEE International Symposium on Integrated Network Management-Workshops, 2009.

[6] Baioco, G., Garcia, A. Implementation and application of a well-founded configuration management ontology, IEEE/IFIP Network Operations and Management Symposium Workshops (NOMS Workshops), 2010.

[7] Bodart, F., Patel, A, Sim, M. and Weber, R. Should Optional Properties Be Used in Conceptual Modeling? A Theory and Three Empirical Tests, Information Systems Research (12:4), 2001, pp. 384 405.

[8] Bottazi, E. and Ferrario, R. Preliminaries to a DOLCE Ontology of Organizations, International Journal of Business Process Integration and Management, vol. 4, no. 4, 2009, pp. 225-238.

[9] Bunge, M. Ontology II: A World of Systems. Treatise on Basic Philosophy. Vol. 4. Reidel Publishing Company, Dordrecht, Holland, 1979.

[10] Cardoso, E. C. S., et al. Semantic Integration of Goal and Business Process Modeling. IFIP International Conference on Research and Practical Issues of Enterprise Information Systems (CONFENIS 2010). 2010

[11] Castelfranchi, C. and Falcone, R. Towards a Theory of Delegation for Agent-Based Systems. Robotics and Autonomous Systems, 24(24), 1998, pp. 141-157.

[12] Davis, I.G., Rosemann, M. and Green, P. F. Exploring proposed ontological issues of ARIS with different categories of modelers, In: Proceedings of the Australasian Conference on Information Systems, Hobart, Australia, 2000.

[13] Davis, R. Business Process Modeling with ARIS - A Practical Guide, Springer, 2001.

[14] Dignum, V. A Model for Organization Interaction: Based on Agents, Founded in Logic. The Netherland. 2004.

[15] DODAF, DoD Architecture Framework Version 1.5, V. II: Product Descriptions, 2007.

[16] Ferrario, R. and Guarino, N. Towards an Ontological Foundation for Services Science, In Lecture Notes in Computer Science, Vol. 5468/2009, 2009, Berlin, Springer-Verlag

[17] Ferrario, R. and Oltramari, A. Towards a Computational Ontology of the Mind, Proceedings of the 3rd International Conference on Formal Ontology in Information Systems (FOIS), Torino, Italy, 2004.

[18] Fettke, P., Loos, P., Ontological Analysis of Reference Models, in Green, P., Rosemann, M. (eds.), Business Systems Analysis with Ontologies, Idea Group, 2005.

[19] Filipowska, A., Kaczmarek, M., Markovic, I. M. and Kowalkiewicz, X. Z. Organizational Ontologies to Support Semantic Business Process Management, In SBPM, 2009. 
[20] Fox, M.S., Barbuceanu, M., Gruninger, M., An organisation ontology for enterprise modeling: Preliminary concepts for linking structure and behaviour, Computers in Industry, Volume 29, Issues 1-2, 1996, pp. 123-134, doi:10.1016/0166-3615(95)00079-8.

[21] Gailly, F., Geerts, G. and Poels, G. Ontological Reengineering of the REA-EO using UFO, International Workshop on Ontology-Driven Software Engineering, OOPSLA 2009.

[22] Gärdenfors, P. Conceptual Spaces: the Geometry of Thought, MIT Press, USA, 2000.

[23] Gemino, A. and Wand, Y. Complexity and Clarity in Conceptual Modeling: Comparison of Mandatory and Optional Properties, Data \& Knowledge Engineering (55:3), 2005, pp. 301-326.

[24] Green, P.F. and Rosemann, M. Integrated Process Modelling: An ontological evaluation, Information Systems, 25(2), 2000, pp. 73-87.

[25] Green, P.F. and Rosemann, M., Perceived ontological weaknesses of process modeling techniques: Further evidence, In Proc. 10th European Conference on Information Systems, 2002, pp. 312-321.

[26] Green, P. F. and Rosemann, M. Ontological Analysis of Business Systems Analysis Techniques: Experiences and Proposals for and Enhanced Methodology, In Business Systems Analysis with Ontologies, , Idea Group, 2005.

[27] Green, P., Indulska M. and Rosemann, M. A Reference Methodology for Conducting Ontological Analyses, Proceedings of the 23rd International Conference on Conceptual Modeling, ER 2004, Lecture Notes in Computer Science, 2004, Volume 3288/2004, pp. 110-121, Springer, 2004.

[28] Guarino, N. and Guizzardi, G. In the Defense of Ontological Foundations for Conceptual Modeling. Scandinavian Journal of Information Systems, Vol. 18, No. 1, 2006.

[29] Guarino, N. and Welty, C. Evaluating ontological decisions with OntoClean. Communications of the ACM, 45, 2, Feb. 2002, pp. 61-65.

[30] Guizzardi, G. Ontological Foundations for Structural Conceptual Models, Ph.D. Thesis, CTIT PhD-thesis, University of Twente, The Netherlands, 2005.

[31] Guizzardi, G. The Problem of Transitivity of Part-Whole Relations in Conceptual Modeling Revisited, 21st International Conference on Advanced Information Systems Engineering (CAISE'09), Amsterdam, The Netherlands, 2009.

[32] Guizzardi, G., Falbo, R. and Guizzardi, R. S. S. Grounding Software Domain Ontologies in the Unified Foundational Ontology (UFO): The Case of the ODE Software Process Ontology, XI Iberoamerican Conference on Software Engineering (CIbSE'2008), Recife, Brazil, 2008.

[33] Guizzardi, G., Ferreira Pires L. and Sinderen, M.V. An Ontology-Based Approach for Evaluating the Domain Appropriateness and Comprehensibility Appropriateness of Modeling Languages, In ACM/IEEE 8th International Conference on Model Driven Engineering Languages and Systems. Lecture Notes in Computer Science LNCS 3713, Springer-Verlag, 2005.

[34] Guizzardi, G., Wagner, G. Towards and Ontological Foundation of Agent-Based Simulation, 17th International Winter Simulation Conference (WSC 2011), Phoenix, USA, 2011.

[35] Guizzardi, G.; Wagner, G. Some Applications of a Unified Foundational Ontology in Business Modeling, Ontologies and Business Systems Analysis, Michael Rosemann and Peter Green (Eds.), IDG Group Publisher, 2005.

[36] Guizzardi, R.S.S., Guizzardi, G., Perini, A. and Mylopoulos, J. Towards an Ontological Account of Agent Oriented Goals, Software Engineering for Multi-Agent Systems, vol. 5, Springer-Verlag, 2007.

[37] Guizzardi, G., Falbo, R. A. and Guizzardi, R. S. S. Grounding Software Domain Ontologies in the Unified Foundational Ontology (UFO): The case of the ODE Software Process Ontology. In XI Iberoamerican Workshop on Requirements Engineering and Software Environments , Brazil, 2008.

[38] Heller,B. and Herre, H. Ontological Categories in GOL, Axiomathes, 14(1), Kluwer Academic Publishers, 2004, pp. 57-76.

[39] Jonkers, H. and et al, Concepts for modeling enterprise architectures, In special issue on Architecture in IT of the International Journal of Cooperative Information Systems, pp. 257-287, 2004.

[40] Květoňová, S. Using of the Ontology in Business Process Modeling Domain, Proceedings of the 12th Conference STUDENT EEICT 2006, Brno, CZ, FEKT VUT, 2006, p. 375-379. 
[41] Lankhorst, M. Enterprise Architecture at Work - Modeling, Communication, and Analysis, SpringerVerlag, 2005.

[42] Laurier, W. and Poels, G. Enterprise Ontology-Based Structuring of Conceptual Data Modeling Patterns, Ghent University, Faculty of Economics and Business Administration, 2009.

[43] Laurier, W., and Poels, G. Poels, Extending REA Models with a Reference Model for Abstraction Mechanisms, 4th International Workshop on Value Modeling and Business Ontologies, Amsterdam, 2009.

[44] Masolo, C., Borgo, S., A. Gangemi, N. Guarino and Oltramari, A. Ontology Library, WonderWeb Deliverable D18, 2003.

[45] Masolo, C., Guizzardi, G., Vieu, L., Bottazzi, E. and Ferrario, R. Relational Roles and Qua Individuals, AAAI Fall Symposium on Roles, an Interdisciplinary Perspective, USA, 2005.

[46] Masolo,C., Vieu, L., Bottazzi, E., Catenacci, C., Ferrario, R., Gangemi, A. and Guarino, N. Social Roles and Their Descriptions, Principles of Knowledge Representation and Reasoning, Proceedings of the Ninth International Conference KR 2004, , AAAI Press, 2004, pp. 267-277.

[47] Ministry of Defence, MOD Architecture Framework (MODAF), http://www.mod.uk/DefenceInternet/AboutDefence/WhatWeDo/InformationManagement/MODAF/, 2010.

[48] Moody, D., The 'Physics' of Notations: Toward a Scientific Basis for Constructing Visual Notations in Software Engineering, IEEE Transactions on Software Engineering, Vol. 35, No. 6, pp. 756-779, 2009.

[49] Mulligan, K.; Smith, B. A Relational Theory of the Act., Topoi (5/2), p.115-30, 1986.

[50] Recker, J., Rosemann, M., Green, P. and Indulska, M. Do Ontological Deficiencies in Modeling Grammars Matter? MIS Quarterly, Vol. 35, No. 1, pp. 57-79, 2011.

[51] Recker,J., Indulska, M., Rosemann, M. and Green, P. The ontological deficiencies of process modeling in practice, European Journal of Information Systems, vol. 19, pp. 501-525, Jun. 2010.

[52] Recker, J., Indulska, M., Rosemann, M. and Green, P., Business process modeling : a comparative analysis. Journal of the Association for Information Systems, 10(4), 2009, pp. 333-363.

[53] RM-ODP-ISO-ISO/ITU-T, Open Distributed Processing - Reference Model. In: Open Distributed Processing - Reference Model, 1995.

[54] Santos Jr., P. S., Almeida, J. P. A. and Guizzardi, G. An Ontology-Based Semantic Foundation for ARIS EPCs, In: 25th ACM Symposium on Applied Computing (Enterprise Engineering Track), 2010.

[55] Santos Jr., P. S., Almeida, J. P. A. and Pianissolla, T. L. Uncovering the Organisational Modelling and Business Process Modeling Languages in the ARIS Method, International Journal of Business Process Integration and Management (IJBPIM), Vol. 5, No. 2, 2011, pp. 130-143.

[56] Scheer, A.W. ARIS - Business Process Modeling, Third Edition. Springer,1999.

[57] Searle, J. Mind, Language and Society, Basic Books, 2000.

[58] Shanks, G., Tansley, E. and Weber, R. Using Ontology to validate conceptual models. Communications of the ACM, Vol. 46, No .10, pp. 85-89, 2003.

[59] Shanks, G., Tansley, E., Nuredini, J., Tobin, D. and Weber, R. Representing Part-Whole Relations in Conceptual Modeling: An Empirical Evaluation, MIS Quarterly (32:3), 2008, pp. 553-573

[60] Sierhuis, M. Modeling and Simulating Work Practice. BRAHMS: a multiagent modeling and simulation language for work system analysis and design, Ph.D. thesis, Social Science and Informatics (SWI), University of Amsterdam, SIKS Dissertation Series No. 2001-10, Amsterdam, The Netherlands, 2001.

[61] Simons, P.M. Parts. An Essay in Ontology, Oxford: Clarendon Press, 1987

[62] Sowa, J.F., and Zachman, J.A. Extending and formalizing the framework for information systems architecture, IBM Systems Journal, v.31 n.3, pp. 590-616, 1992.

[63] Steimann,F. On the representation of roles in object-oriented and conceptual modeling, Data and Knowledge Engineering, vol. 35, pp. 83-106, 2000.

[64] Textor, M., States of Affairs, The Stanford Encyclopedia of Philosophy (Summer 2012 Edition), Zalta, E.N. (ed.), 2012, http://plato.stanford.edu/archives/sum2012/entries/states-of-affairs/.

[65] The Open Group, ArchiMate 1.0 Specification, http://www.opengroup.org/archimate/doc/ts_archimate/. 
[66] TOGAF, The Open Group Architectural Framework (TOGAF 8.1.1 'The Book'), Van Haren Publishing, 2008.

[67] Wand, Y. and Weber, R. An ontological evaluation of systems analysis and design methods, In E. Falkenberg and P. Lingreen, editors, Information System Concepts: An In-Depth Analysis. Elsevier Science Publishers B.V., North-Holland, 1989.

[68] Wand, Y. and Weber, R. Mario Bunge's Ontology as a formal foundation for information systems concepts, In Weingartner, P. \& Dorn, G.J.W. (eds.), Studies on Mario Bunge's Treatise, Rodopi, Atlanta, 1990.

[69] Weber, R. Ontological Foundations of Information Systems, Coopers \& Lybrand, Melbourne, Australia, 1997

[70] Wieringa, R.J., Jonge, W., Spruit, P.A. Using dynamic classes and role classes to model object migration. Theory \& Practice of Object Systems, 1(1), 1995, pp. 61-83.

[71] Winston,M. E., Chaffin, R. and Herrman,D. A taxonomy of part-whole relations, Cognitive Science 11, 1987, pp. 417-444.

[72] Zur Muehlen, M., Indulska, M. and Kamp, G. Business process and business rule modeling languages for compliance management: a representational analysis. In Tutorials, posters, panels and industrial contributions at the 26th international conference on Conceptual modeling - Volume 83 (ER '07), Vol. 83. Australian Computer Society, 2007, pp. 127-132.

[73] Zur Muehlen, M., Indulska, M. Modeling languages for business processes and business rules: A representational analysis, Information Systems 35 (4), 2010, pp. 379-390. 